
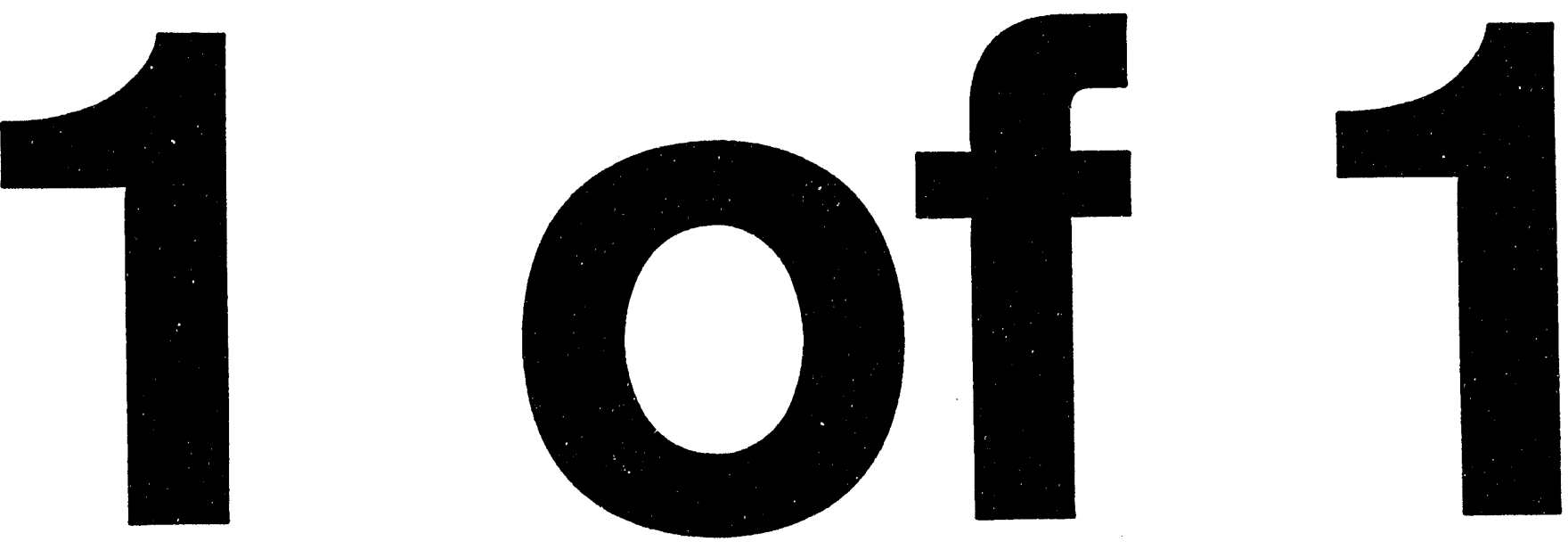


\section{Maintenance Study for W-340 Waste Retrieval System}

C. Christensen

C. C. Conner

J. P. Sekot

Published May 1994

Idaho National Engineering Laboratory

EG\&G Idaho, Inc.

Idaho Falls, Idaho 83415

Prepared for the

U.S. Department of Energy

Office of Environmental Management

Under DOE Idaho Operations Office

Contract DE-AC07-76ID01570 


\section{Maintenance Study for W-340 Waste Retrieval System}

EGG-WTD-11310

Prepared by

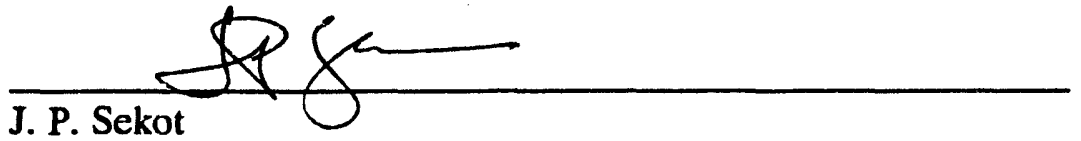

EG\&G Idaho, Inc.

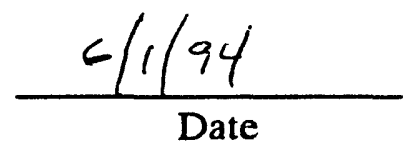

Reviewed by

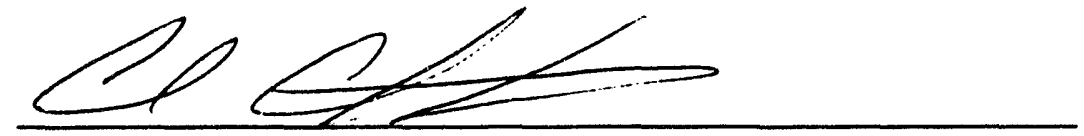

C. Christensen

Westinghouse Idaho Nuclear Company

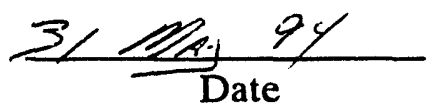

Approved by

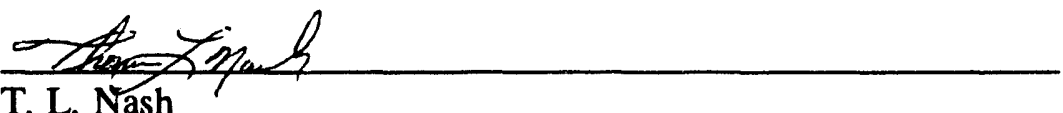

T. L. Nash

$\frac{31 M_{4} 94}{\text { Date }}$

Office of Waste Technology Development 


\begin{abstract}
This study was performed to identify attributes and maintainability requirements for the Tank Waste Retrieval System (TWRS). The system will be developed for Westinghouse Hanford Company in Richland, Washington, as an integrated system to perform waste removal in Tank C-106 and, thus, demonstrate technologies for tank remediation that will satisfy requirements of the Tri-Party Agreement. The study examines attributes of the TWRS, scope of maintenance operations required for the TWRS, maintenance requirements, and potential methods of performing maintenance functions. Recommendations are provided for consideration in the development of both the conceptual design and performance specification, which will be used in procuring the W-340 Waste Retrieval System.
\end{abstract}




\section{SUMMARY}

The U.S. Department of Energy (DOE), Richland Operations Office, has established the Tank Waste Remediation System (TWRS) to resolve environmental and safety issues related to underground waste storage tanks. The waste retrieval program within TWRS includes a series of retrieval activities in both single storage tank systems and double storage tank systems. Demonstration of single storage tank waste retrieval technology is required by milestone M-45-03-T01 of the Hanford Site's Federal Facility Agreement and Consent Order (Tri-Party Agreement). This milestone requires demonstrating the removal of at least $95 \%$ of the radioactive and chemical waste inventory in one tank. Tank 241-C-106 has been selected by DOE for this demonstration. Project W-320 will use a sluicing technology to demonstrate retrieval of most of the high heat sludge from tank C-106. However, sluicing is not expected to remove the 1 to 2 -ft thick layer of hardened sludge at the bottom of the tank. Therefore, Project W-340 has been established to remove the hardened sludge using a long reach manipulator (LRM) operating through a center tank opening. Successful completion of both W-320 and W-340 will satisfy the Tri-Party Agreement milestone.

This study identifies attributes and maintainability requirements of the LRM TWRS. The basic design concept for the LRM TWRS is described in Wallace (1993). This study is intended to outline attributes/system required for the LRM TWRS and identify maintenance requirements and potential elements that will help simplify the necessary maintenance functions. Recommendations identified in this report will be given consideration in the development of both the conceptual design and performance specification to be used in procuring the W-340 Waste Retrieval System. 


\section{CONTENTS}

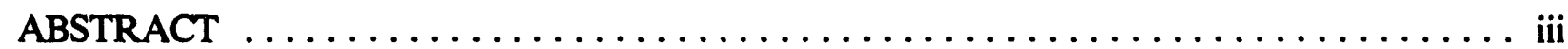

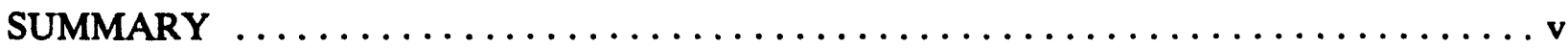

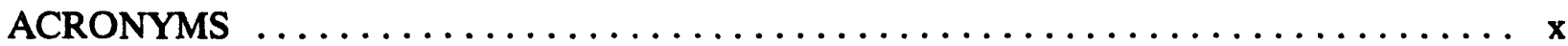

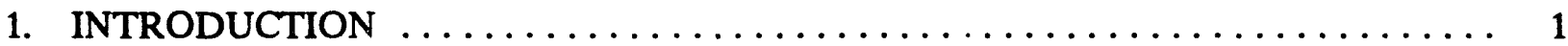

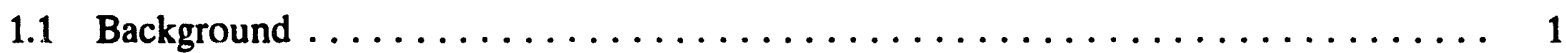

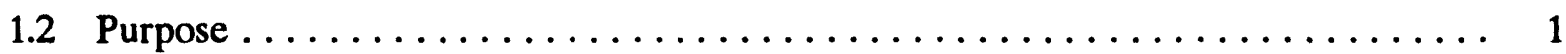

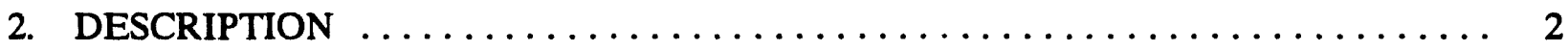

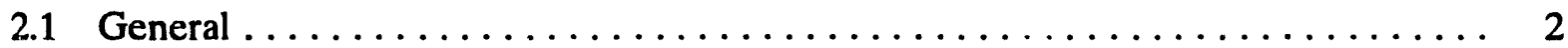

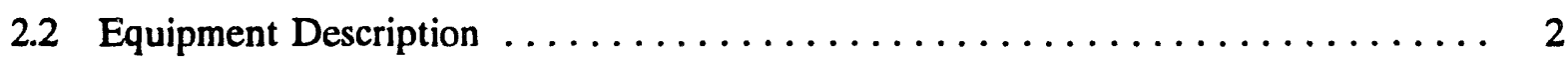

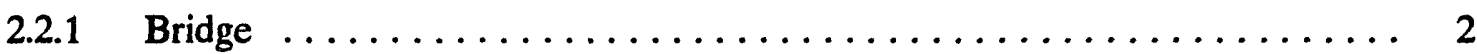

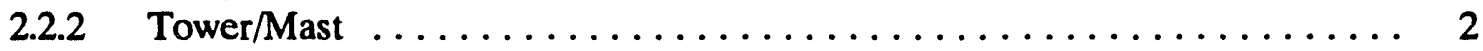

2.2.3 Waste Retrieval Deployment System ..................... 4

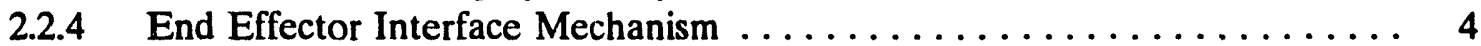

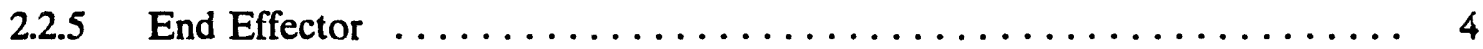

2.2.6 End Effector Exchange Module $\ldots \ldots \ldots \ldots \ldots \ldots \ldots \ldots \ldots \ldots$

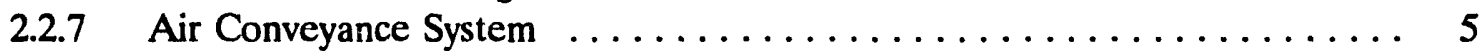

2.2 .8 Tank/Structure Interface $\ldots \ldots \ldots \ldots \ldots \ldots \ldots \ldots \ldots \ldots \ldots \ldots$

$2.2 .9 \quad$ Utilities Module . . . . . . . . . . . . . . . . . . . . . 6

2.2.10 Heating, Ventilating, and Air Conditioning $\ldots \ldots \ldots \ldots \ldots \ldots \ldots$

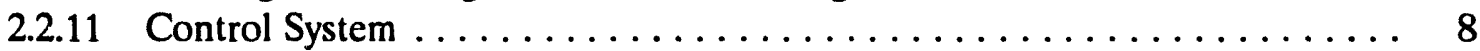

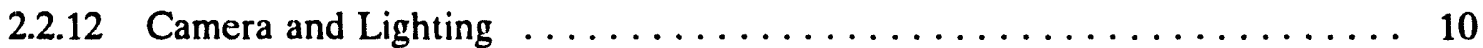

2.2.13 Decontamination $\ldots \ldots \ldots \ldots \ldots \ldots \ldots \ldots \ldots \ldots \ldots \ldots \ldots$

3. SYSTEM ATTRIBUTES $\ldots \ldots \ldots \ldots \ldots \ldots \ldots \ldots \ldots \ldots \ldots \ldots \ldots \ldots \ldots \ldots \ldots$

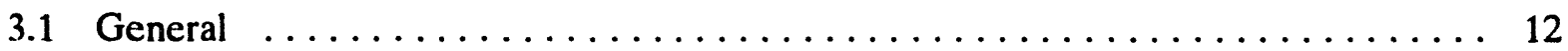

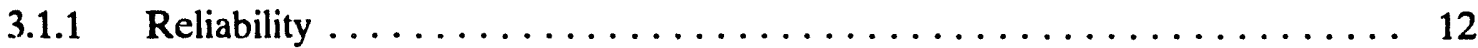

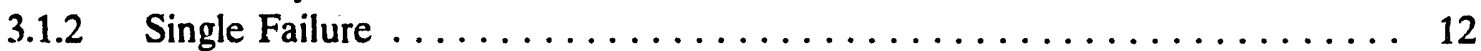

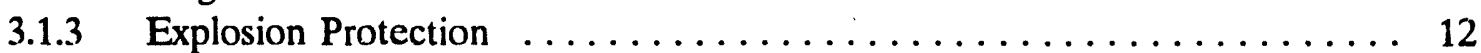

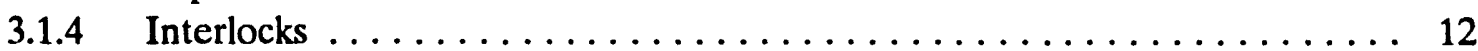

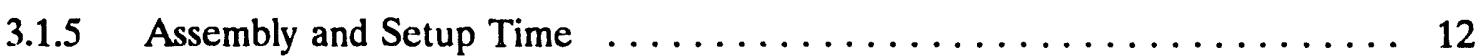

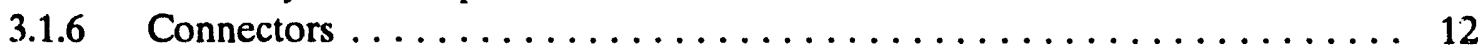

3.1.7 Common Components .......................... 12

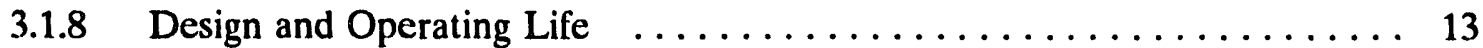

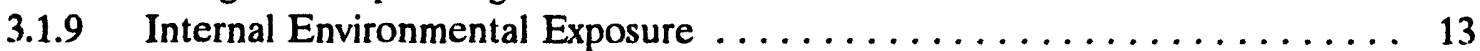


3.1.10 External Environment $\ldots \ldots \ldots \ldots \ldots \ldots \ldots \ldots \ldots \ldots \ldots \ldots \ldots \ldots$

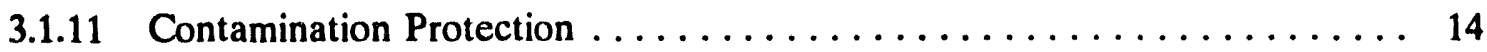

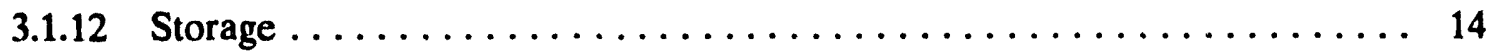

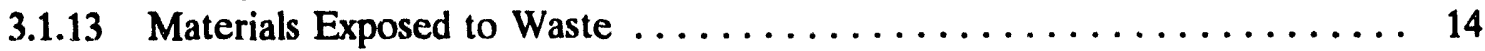

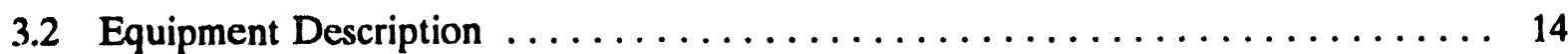

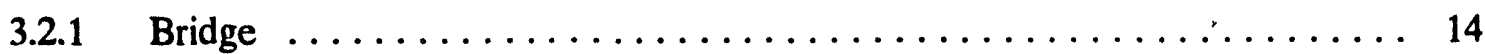

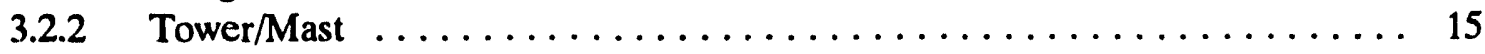

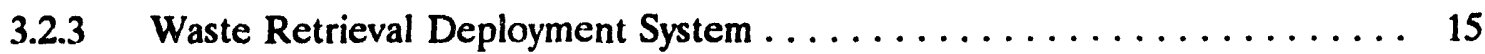

3.2.4 End Effector Interface Mechanism $\ldots \ldots \ldots \ldots \ldots \ldots \ldots \ldots \ldots \ldots \ldots \ldots$

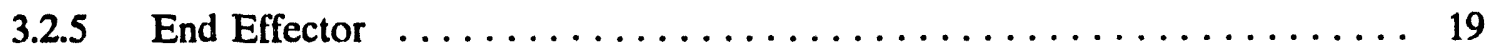

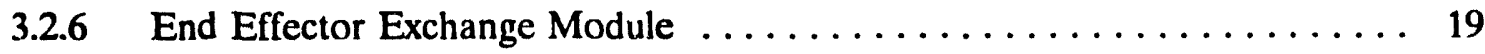

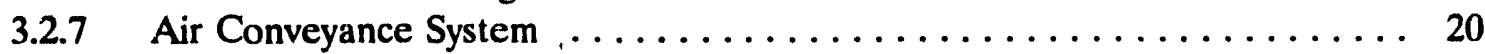

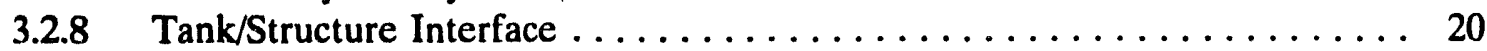

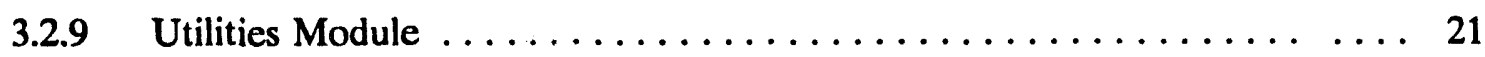

3.2.10 Heating, Ventilating, and Air Conditioning $\ldots \ldots \ldots \ldots \ldots \ldots \ldots \ldots \ldots$

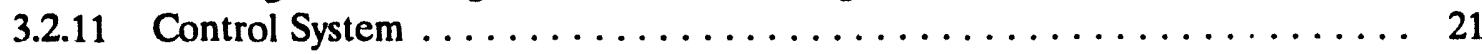

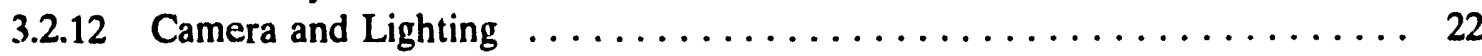

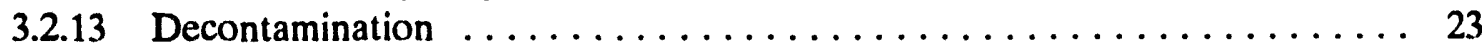

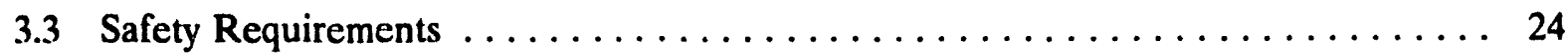

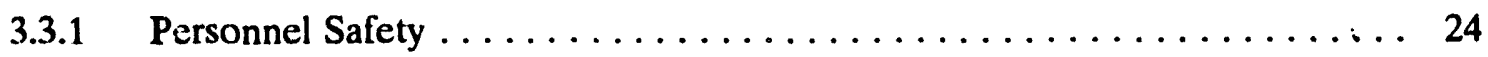

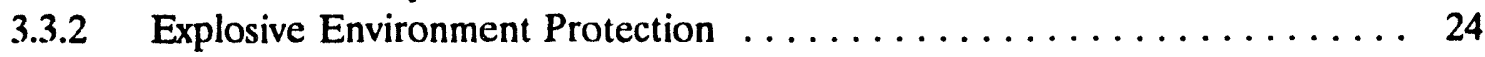

3.3.3 Equipment Protection . . . . . . . . . . . . . . . . . . . 24

3.3.4 Special End Effector Exchange Module Safety Considerations . . . . . . . 24

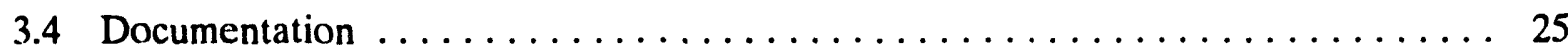

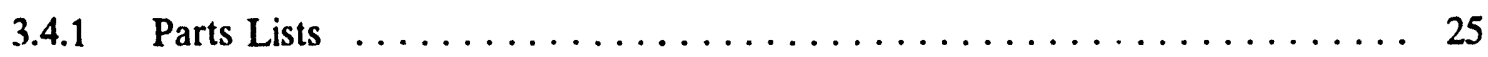

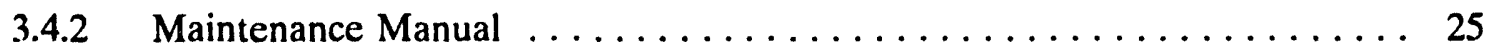

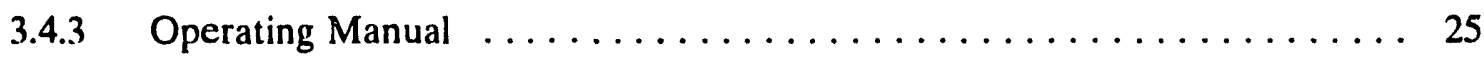

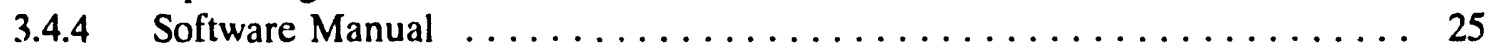

4. MAINTENANCE REQUIREMENTS $\ldots \ldots \ldots \ldots \ldots \ldots \ldots \ldots \ldots \ldots \ldots \ldots$

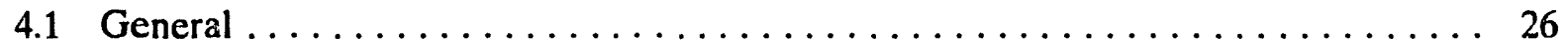

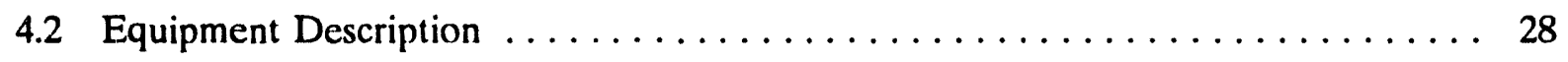

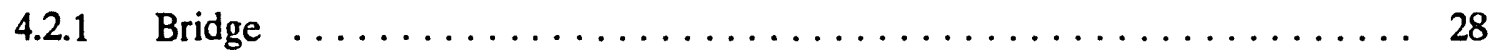

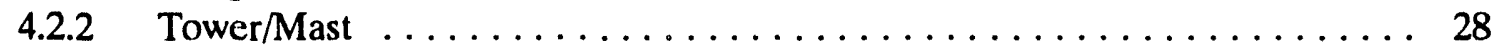

4.2.3 Waste Retrieval Deployment System ................... 28

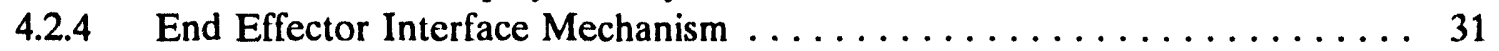

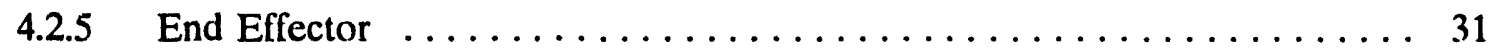

4.2.6 End Effector Exchange Module $\ldots \ldots \ldots \ldots \ldots \ldots \ldots \ldots \ldots \ldots \ldots$ 


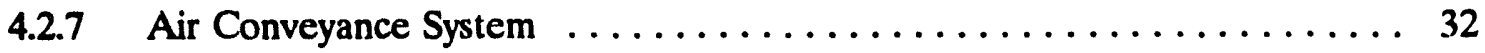

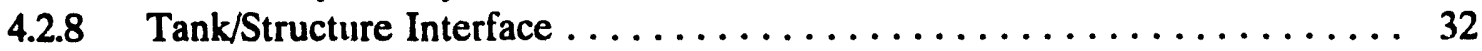

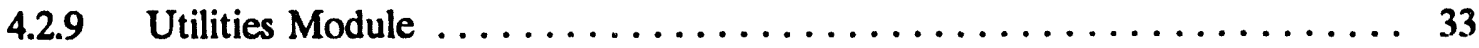

4.2.10 Heating, Ventilating, and Air Conditioning $\ldots \ldots \ldots \ldots \ldots \ldots \ldots \ldots$

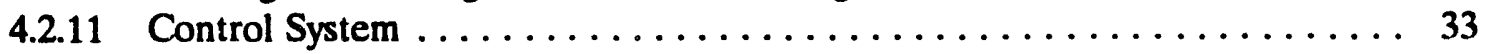

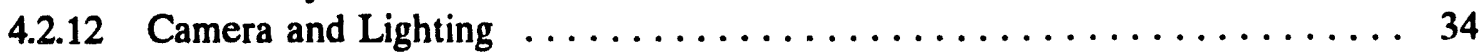

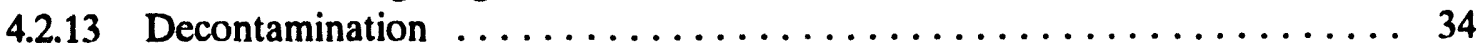

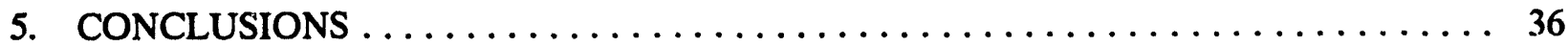

6. RECOMMENDATIONS $\ldots \ldots \ldots \ldots \ldots \ldots \ldots \ldots \ldots \ldots \ldots \ldots \ldots \ldots \ldots$

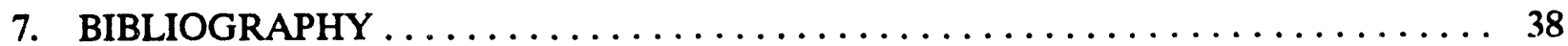

\section{FIGURES}

1. W-340 waste retrieval system. $\ldots \ldots \ldots \ldots \ldots \ldots \ldots \ldots \ldots \ldots \ldots \ldots \ldots \ldots \ldots$

2. HVAC airflow diagram. .......................... 7

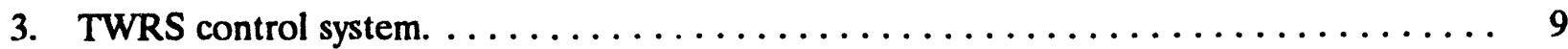

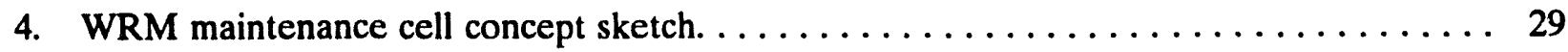




\section{ACRONYMS}

ac

ASHRAE

dc

DOE

EEIM

HEPA

HVAC

IEEE

LRM

NEC

SCC

TWRS

WHC

WRM
Alternating current

American Society of Heating, Refrigeration, and Air Conditioning engineers

Direct current

U.S. Department of Energy

End effector interface mechanism

High efficiency particulate air

Heating, ventilating, and air conditioning

Institute of Electrical and Electronic Engineers

Long reach manipulator

National Electric Code

Supervisory control computer

Tank Waste Remediation System

Westinghouse Hanford Company

Waste retrieval manipulator 


\section{Maintenance Study for W-340 Waste Retrieval System}

\section{INTRODUCTION}

\subsection{Background}

The U.S. Department of Energy (DOE), Richland Operations Office, has established the Tank Waste Remediation System (TWRS) to resolve environmental and safety issues related to underground waste storage tanks. The waste retrieval program within TWRS includes a series of retrieval activities in both single storage tank systems and double storage tank systems. Demonstration of single storage tank waste retrieval technology is required by milestone M-45-03-T01 of the Hanford Site's Federal Facility Agreement and Consent Order (Tri-Party Agreement). This milestone requires demonstrating the removal of at least $95 \%$ of the radioactive and chemical waste inventory in one tank. Tank 241-C-106 has been selected by DOE for this demonstration. Project W-320 will use a sluicing technology to demonstrate retrieval of most of the high heat sludge from tank C-106. However, sluicing is not expected to remove the 1 to 2 -ft thick layer of hardened sludge at the bottom of the tank. Therefore, Project W-340 has been established to remove the hardened sludge using a long reach manipulator (LRM) operating through a center tank opening. Successful completion of both W-320 and W-340 will satisfy the Tri-Party Agreement milestone.

The LRM will be developed for Westinghouse Hanford Company (WHC) in Richland, Washington, as an integrated system to assist in removing 1 to $2 \mathrm{ft}$, high-level, hardened sludge heel located on the bottom of underground storage tank 241-C-106.

Tank 241-C-106 is located in the C Tank Farm in the 200 east area of the Hanford Site near Richland. It is a 533,000 gal, 75 - $\mathrm{ft}$ diameter, single-shelled, underground storage tank that currently contains stored high-level radionuclide waste collected from multiple waste management and isotope recovery operations. The waste currently in tank $\mathrm{C}-106$ contains radionuclides that generate heat at a rate greater than $0.1 \mathrm{BTU} / \mathrm{gal} /$ hour and have greater than 100 nanocuries per gram $(\mathrm{nCi} / \mathrm{g})$ transuranic content, which qualifies the sludge as both high-level waste and transuranic waste. The chemical composition of the sludge also classifies the waste as "listed" in accordance with Washington Administrative Code 173-303.

Several risers of various diameters (up to $42 \mathrm{in.}$ in diameter) penetrate the tank. The preconceptual design of the waste retrieval considered in this report is based on tank entry through a 42-in. diameter riser that will be installed in a new penetration in the existing heel pit.

\subsection{Purpose}

This study identifies attributes and maintainability requirements of the LRM TWRS. The basic design concept for the LRM TWRS is described in Wallace (1993). This study is intended to outline attributes/system required for the LRM TWRS and identify maintenance requirements and potential elements that will help simplify the necessary maintenance functions. Recommendations identified in this report will be given consideration in the development of both the conceptual design and performance specification to be used in procuring the W-340 Waste Retrieval System. 


\section{DESCRIPTION}

\subsection{General}

This study is based on the retrieval system presented in Project W-340 Tank 241-C-106 Manipulator Retrieval System (Wallace, 1993). The design of the retrieval system is based on a LRM operating through an opening in the center of the tank dome (see Figure 1). Attached to the end of the manipulator arm is a retrieval tool that breaks up the solid waste (heel) with high-pressure, low-volume water jets. A high velocity, air-vacuum system conveys the waste and injected water to an aboveground accumulation tank. The waste is then slurried with water and pumped to an interim double shell storage tank prior to treatment and disposal.

The manipulator is supported and deployed by a mast that moves vertically within a containment structure mounted on top of a bridge that spans across the top of the tank. The movement, or degrees of freedom, of the deployment mast and manipulator as an integral unit provide complete coverage of the tank interior.

The capability to change end effectors on the manipulator arm is provided by the end effector exchange module, a cell located on the bridge directly above the tank opening. The deployment mast and waste retrieval/waste retrieval manipulator (WRM) operate vertically through this cell, which is equipped with an X-Y transfer table and a 3-ton hoist capable of covering the module area for end effector change out, maintenance, and handling other equipment including the riser plug.

\subsection{Equipment Description}

\subsubsection{Bridge}

The bridge will be a $102-\mathrm{ft}$ long, $34-\mathrm{ft}$ wide, $17-\mathrm{ft}$ high structural steel truss mounted on foundations on two sides of the tank, spanning the tank to prevent structural loading to the top of the tank. It will support the waste retrieval equipment support tower, end effector exchange module, and air conveyance module.

\subsubsection{Tower/Mast}

2.2.2.1 Support Tower. The support tower will be a $16 \times 16 \times 50$-ft tall, structural steel tower mounted on the bridge to enclose and support the retrieval equipment. Adjustable bracing and structural members will be used to secure the support mast to the tower.

2.2.2.2 Support Mast. The support mast will be mounted on top of the end effector exchange module and inside the support tower. It will be part of the main support structure housing the vertical deployment mast and WRM when they are in the retracted or stowed (upward) position. The support mast will be a stationary outer confinement for the retrieval system. 


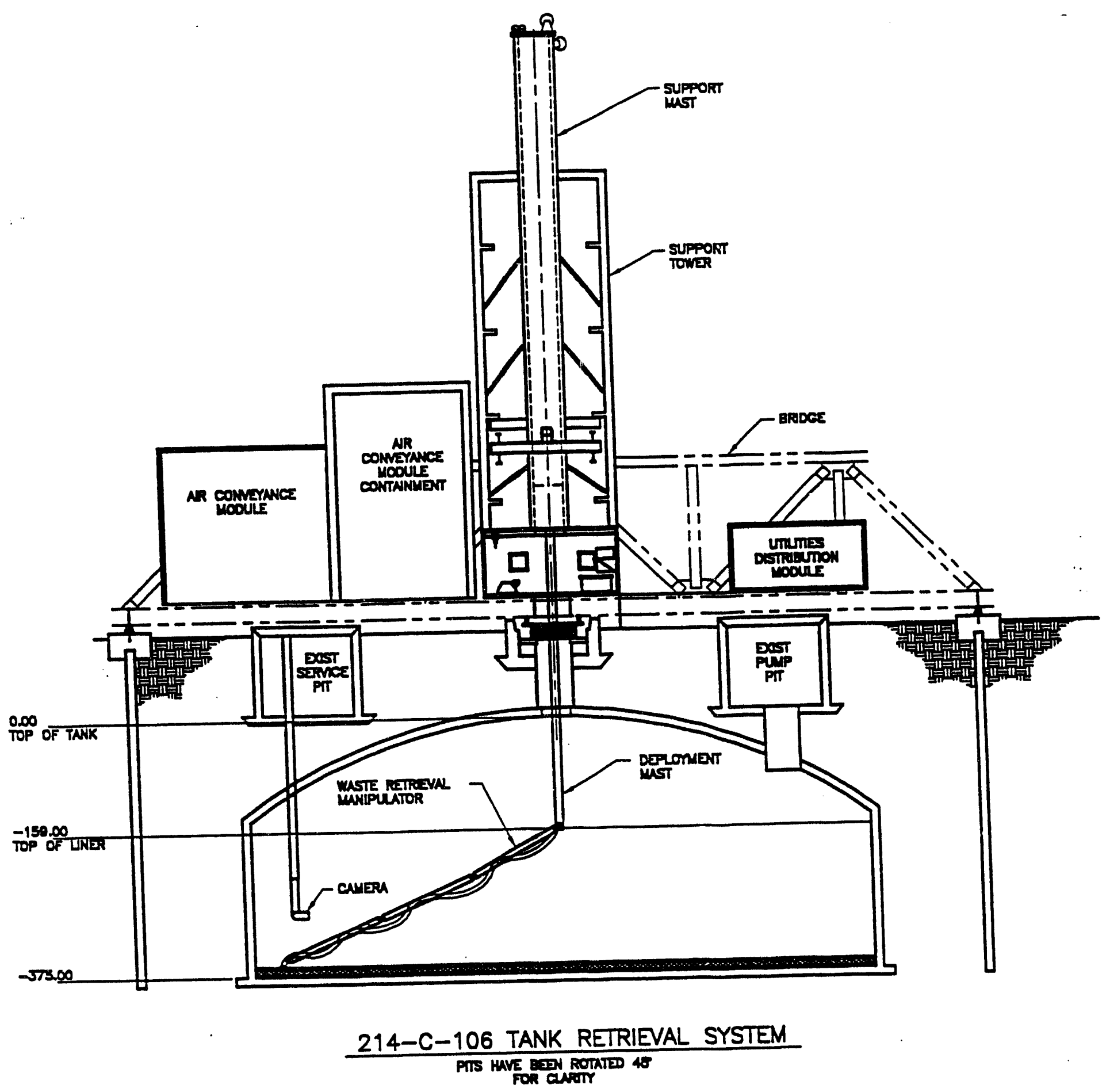

Figure 1. W-340 waste retricval system. 


\subsubsection{Weste Retrieval Deployment System}

2.2.3.1 Deployment Mast. The deployment mast will include the portion of the TWRS that provides the structural support and alignment features for the operation of the WRM. The deployment mast will be a rigid structure that supports the WRM during its deployment and operation inside the tank and transfers the operating loads to the support mast. It will be comprised of equipment required for extension and retraction of the WRM into and out of tank. The deployment mast and WRM will both be supported by and contained within the framework of the support mast. On the present design, the deployment mast moves vertically within the support mast using a wire rope and hoist system and is guided vertically and laterally supported by two sets of roller bearings located on the upper end as identified in the conceptual design (Wallace, 1993). Rotation of the deployment mast and WRM, as an integral unit, around their collinear centerlines will be accomplished by a hydraulic actuator attached to the top end of the deployment mast. Consideration should be given to moving the rotation feature to the top of the WRM because this may facilitate operation and maintenance.

2.2.3.2 Waste Retrieval Manipulator. The WRM will position the end effector within the tank. It will be approximately $40 \mathrm{ft}$ long, and in the conceptual design (Wallace, 1993) vill cons st of a minimum of four sections. The lower three sections (each approximately $12 \mathrm{ft}$ long) will incorporate hydraulic actuators capable of providing 90 degree motion in a vertical plane. A hydraulic actuator at the wrist of the WRM will provide pitch capability to lend greater dexterity to the motion of the end effector. A rotation joint could be provided next to the end effector interface plate to allow \pm 180 degree rotation of the end effector. The configuration of the WRM shall allow the end effector to be positioned at any location in the tank interior and with the end effector at any orientation within the C-106 tank.

\subsubsection{End Effector Interface Mechanism}

The end effector will couple to the WRM by means of the end effector interface mechanism (EEIM). The EEIM serves as the mechanical interface between the WRM and end effector for transferring end effector loads and interconnecting pneumatic, hydraulic, electrical, and other services for the end effector. The EEIM will be a quick change tool device consisting of two interface plates. One will be attached permanently to the end of the manipulator, and the other will be attached to the end effecior. All utilitics needed to operate the end effector will be routed along the length of the WRM and terminate at their respective connectors on the EEIM. Upon proper mating, the two plates will be secured together by a latching mechanism.

\subsubsection{End Effector}

The design of the end eff tor will be based on the use of high-pressure $(30,000$ to $60,000 \mathrm{psi}$ developed using an intensifier pump), low-volume water jets to dislodge and break up the waste in preparation for retrieval with the air conveyance system. The jets will be mounted inside a shroud to reduce splashing and direct the air flow. Impingement of the high-pressure jets will result in a significant reactive force directed perpendicular to the face of the shroud. This force will then be transmitted to the WRM by the wrist joint. Jet pulsing could result in significant dynamic loading to the WRM. 
The end effector will be fitted with one of the two mating interface plates for hookup to the EEIM. It will incorporate connectors for the high-pressure water, hydraulics, pneumatics, electrical, and other required utilities and also transfer operating loads to the WRM through EEIM. Another separate remote coupling system will be needed for the air conveyance hose. Camera and lights located on the WRM will allow visual observation of the end effector operations.

7 end effector will be remotely controlled from a rack-mounted base control station located insid. s. TWRS control trailer several hundred feet away from the tank.

\subsubsection{End Effector Exchange Module}

Change-out, minor maintenance, and repair of the end effectors will takes place in the end effector exchange module, which will be an enclosed, shielded cell, approximately $16 \mathrm{ft}^{2} \times 10 \mathrm{ft}$ high, centered and located beneath the mast, and encircled by galleries where personnel can view and service equipment through glove ports. Areas within the module will be reserved for storage of the end effector(s), riser shield plug, tools, and handling equipment. Exchange of end effectors will be normally an automated process; however, glove ports, a double containment waste load-out chamber, hoists, transfer table, and handling tools are planned to allow manual assembly and disassembly of the end effectors and, possibly, the WRM.

The end effector will be stored in the exchange system. The system shall be capable of moving and accurately positioning the end effector to any location within the interior of the end effector exchange module and mating it to the WRM. The system should be able to raise the end effector to mate with the WRM interface plate. The bridge mounted 3-ton hoist, also capable of covering the module area, shall be used for handling the riser plug, end effectors, and other equipment.

\subsubsection{Air Conveyance System}

2.2.7.1 Air Conveyance Module. The air conveyance module will be a structure located on the bridge adjacent to the support tower. It will house the equipment needed for the pneumatic removal, accumulation, and storage of waste from the tank C-106. Equipment requiring shielding (air conveyance hose reel, cyclone air/waste separator, waste accumulation sludge tank, and secondary knock-out drum) will be located within the shielded portion of the module. Consideration should be given to skid-mounted equipment, lined cargo containers with removable external shielding, and the use of top loading containers to simplify removal at the decontamination facility. All the equipment within the containers shall incorporate features that allow remote cleaning, flushing, decontamination, and removal.

Waste brought into the module through the air conveyance hose will be separated from the air by the cyclone separator and deposited into the accumulation tank while the air continues on into the knock-out drum, a secondary separation tank. The semidry waste deposited in the accumulation tank will then be mixed with raw water for pumping, and air from the knock-out drum will be heated and returned to the tank C-106.

2.2.7.2 Air Conveyance Hose. The air conveyance hose will be a flexible duct that carries the waste retrieved from tank $\mathrm{C}$-106. It will consist of two separate lengths, one running along and fixed to the entire length of the WRM. The other length will be dispensed from an 8-ft diameter reel 
and routed for entry into the tank through an opening in the support module. Each section of the WRM will have a length of hose attached with sufficient slack to allow rotating each manipulator joint. The hose attachment devise on the manipulator will rotate and move along the length of each WRM section to facilitate extension and compression of the hose.

2.2.7.3 Air Conveyance/Heating, Ventilating, and Air Conditioning. The air conveyance heating, ventilating, and air conditioning (HVAC) system will consist of a supply and exhaust air train. The supply air train will include a recirculation plenum, prefilter, chilled-water cooling coil, and a centrifugal fan. The exhaust airstream will be sampled by a continuous gas monitoring station and exhausted out the stack.

\subsubsection{Tank/Structure Interface}

The tank/structure interface will be provided by a flexible enclosure, providing containinent with no loads transmitted to the top of the tank. This nonrigid coupling (telescoping/bellows type adapter) between the tank and bridge will interface with the riser access flange. The upper end of this adapter will seal against the underside of an enclosure located underneath the bridge. This enclosure shall also be equipped with decontamination equipment for removing residual waste and contaminants. Wallace (1993) describes the wash down/decontamination system, which will consist of a pressurized heated water source. Further studies recommend the use of a $\mathrm{CO}_{2}$ blasting decontamination system (Reutzel, 1994). The operations shall be performed remotely and viewed by a TV camera located within the washer housing.

\subsubsection{Utilities Module}

The utilities module will be located at ground level near tank C-106 and house equipment required for manipulator operation. Equipment located within this module will include a demineralizer; intensifiers for the end effector water jets; hydraulic motors and power units; and a local control center for manual operation of the WRM. The demineralizer will provide demineralized water to the high-pressure water jet nozzles to prevent plugging. The conceptual design (Wallace 1993) will locate the utilities module on the bridge; however, grouping the equipment with adequate space for maintenance activities would require a building too large for the bridge. Hence, the final design may include relocating the utilities module off the bridge.

As with all systems and components of the TWRS, it is recommended that this module be configured like a cargo container with lifting points, fork lift ports, and cargo doors.

\subsubsection{Heating, Ventilating, and Air Conditioning}

The HVAC system will control the tank environment and confinement of waste by controlling the atmospheric pressure inside the tank, end effector exchange module, and support module by maintaining a constant flow of air from the support module through the end effector exchange module into the tank. The tank HVAC system will tie into existing tank risers for exhaust and intake air and includes equipment mounted on four skids (see Figure 2). 


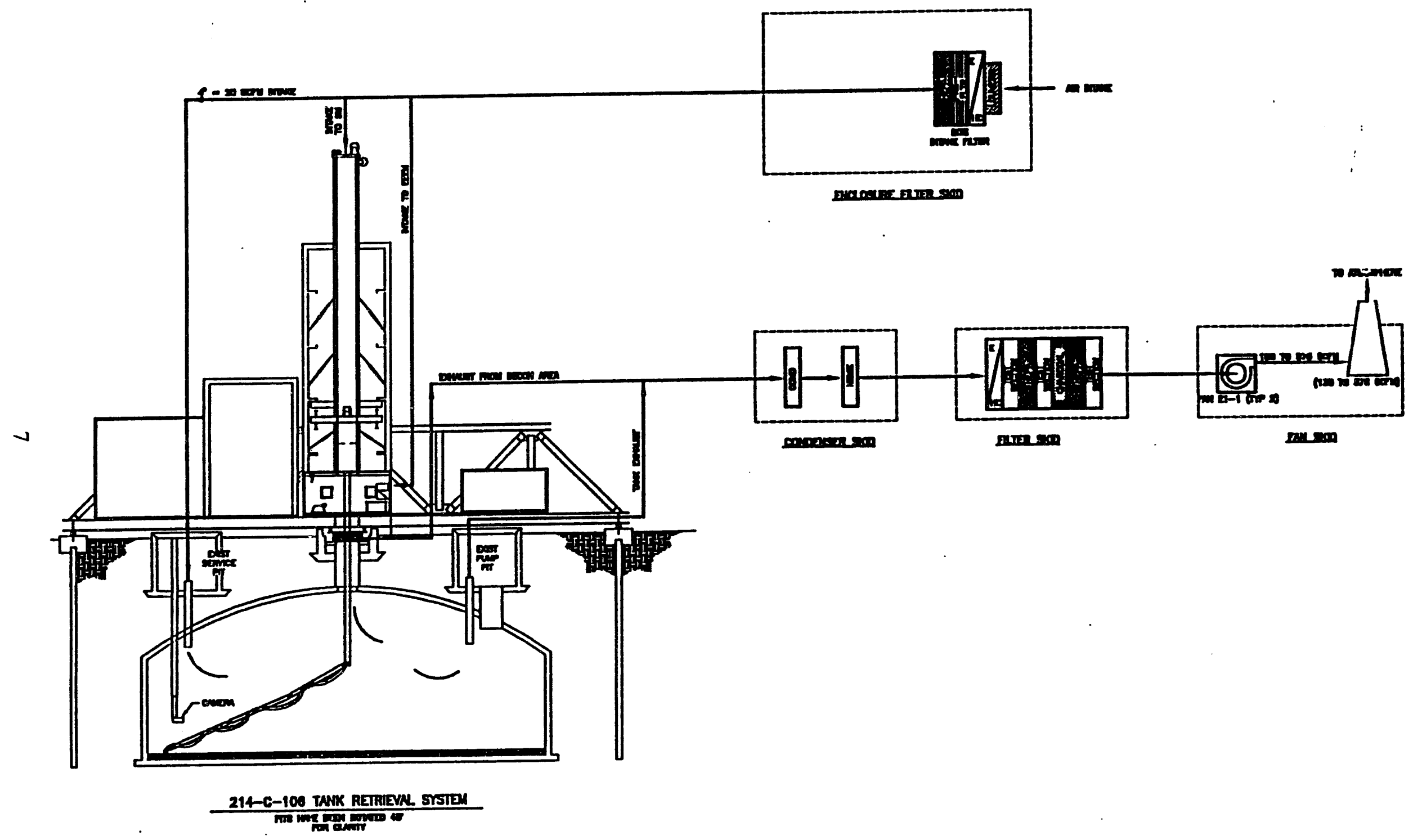

Figure 2. HVAC airflow diagram. 
2.2.10.1 Condenser Skid. The condenser skid will be approximately $12 \mathrm{ft}$ long $\times 8 \mathrm{ft}$ wide $\times$ $10 \mathrm{ft}$ high, containing a condenser heat exchanger and high efficiency mist eliminator. The packaged chiller will be located adjacent to the condenser skid.

2.2.10.2 Filter Skid. Two filter skids will be $23 \mathrm{ft}$ long $\times 8 \mathrm{ft}$ wide $\times 8 \mathrm{ft}$ high, each containing an air train sized for $100 \%$ airflow. Each of the air trains will consist of an electric heating coil, test sections, high efficiency particulate air (HEPA) filters, and activated carbon gas adsorption sections.

2.2.10.3 Fan Skid. The fan skid will be approximately $10 \times 10 \mathrm{ft}$ and will consist of two centrifugal fans, a $30 \mathrm{ft}$ tall, $8 \mathrm{ft}$ diameter, stainless steel, exhaust stack and stack monitoring equipment.

2.2.10.4 Enclosure Fitter Skid. The C-106 tank air intake filter consisting of an intake louver, electric heating coil, American Society of Heating, Refrigeration, and Air Conditioning Engineers (ASHRAE) Standard 52-76 80\% rated refilter, and a HEPA filter will be mounted on the enclosure filter skid.

2.2.10.5 Utility Connections. The HVAC system will require utility connection to filtered water for washing down purposes and a drain condensate system with seal loops and level detection.

\subsubsection{Control System}

The TWRS will have two control systems: the end effector exchange module control system and supervisory controller.

2.2.11.1 Supervisory Controller. The TWRS will be controlled remotely from a trailer positioned several hundred feet away from the tank by a supervisory controller that directs the commands from lower level subsystem controllers (see Figure 3). The subsystem controllers may be located near their respective equipment but will be protected and contained against damaging environments. The supervisory control computer (SCC) will accept operator command inputs and display operating parameters and conditions through a VME-based graphical computer system. Communications for command and data between the SCC and subsystems will be accomplished by an Ethernet system. Some of the control functions required for subsystems interfacing with the supervisory controller will include:

- Deployment Mast-Control is required to vertically position the deployment mast within the tank and support mast.

- Waste Retrieval Manipulator-The WRM has four joints, each with a linear hydraulic actuator, and it also has a hydraulic actuator to provide rotation around its vertical axis. The position of each joint is also monitored by high-resolution, rotary position sensors (angular resolvers) that provide the absolute angular position and velocity of each joint to the control system.

NOTE: Wallace (1993) indicates that both the deployment mast and WRM rotate as an integral unit, which appears to be in conflict with other descriptions 


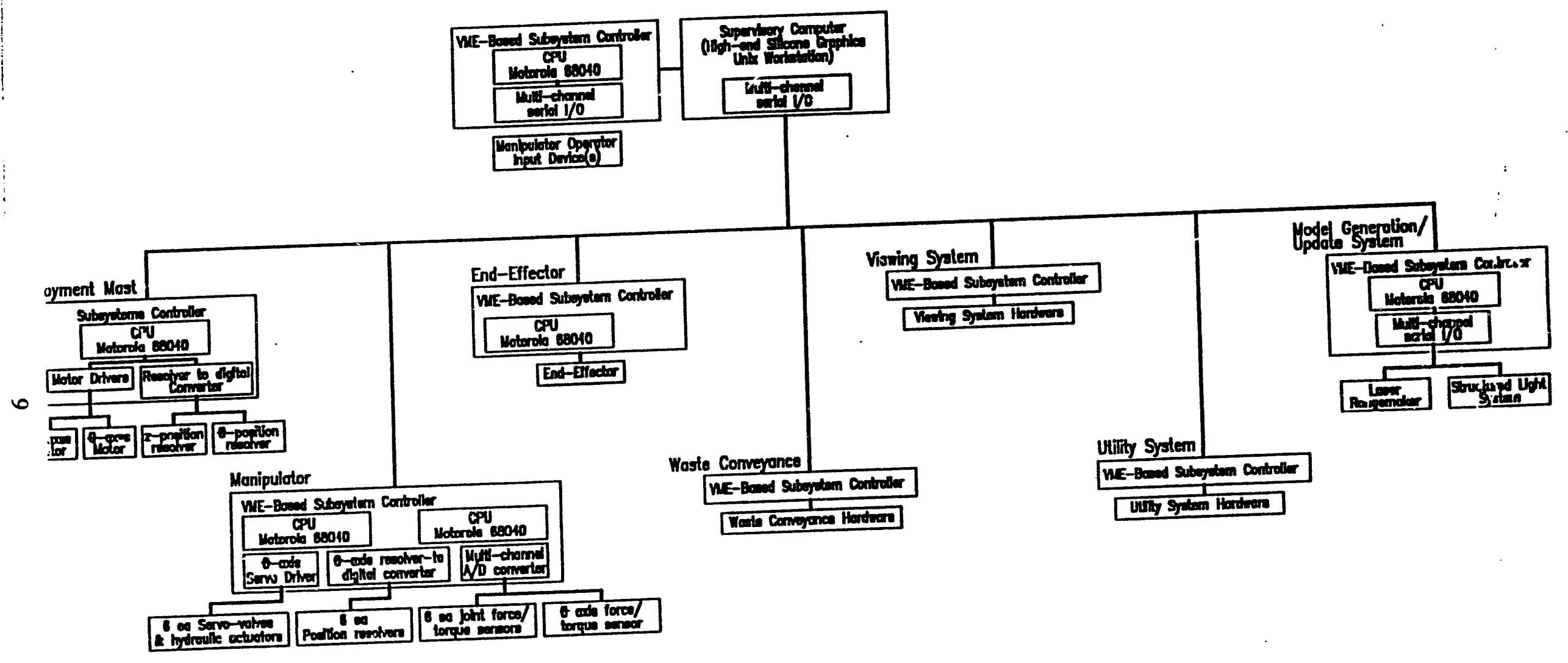

Figure 3. TWRS control system. 
in the reference. Drawings tend to support the description by depicting a drive mechanism for rotation of the deployment mast.

- End Effector-Sensors on the end effector provide feedback to the manipulator's low-level controller to provide real time, servo-positioning control. These sensors include ultrasonic proximity sensors, laser-based proximity/mapping systems, and force sensors.

- End Effector Exchange-Remotely release and attach end effectors.

- Air Conveyance System-The air conveyance system has a dedicated low-level control system to monitor and control the flow of waste, manage the hose, and perform waste characterization activities.

- Utilities-The utilities module has a dedicated low-level control system to monitor the deliveiy and use of utilities and to report any upset conditions to the SCC.

- Cameras and Lighting System-A video camera-based viewing system with a dedicated lowlevel controller communicates with the SCC and operator interface.

- Operator Interface-The operator interface is an integral part of the SCC that accepts commands and provides information to the operator using operator communication devices such as joy sticks, space balls, or other kinematic devices. While in the telerobotic mode, the SCC monitors operator communication for commands that could result in an unsafe operating condition.

- Model Generation/Update System-The SCC is based on a computer model of the tank and retrieval equipment that is generated by means of structured light based sensors and updated by a combination of structured light and laser range finding.

2.2.11.2 Subsystem Controllers. All subsystems will be either Motorola 68040 VME based, or will provide a Motorola 68040 VME-based communications interface to the SCC.

2.2.11.3 End Effector Exchange Module. A control panel/pendant will be provided at the end effector exchange module to control all applicable functions, and operations to relcase and attach end effectors and move the WRM for repair and maintenance.

\subsubsection{Camera and Lighting}

The operator vision system used to assist in the control and monitoring of the waste retrieval process will consist of cameras, video displays, and lights. Both helmet-mounted and panel-mounted displays shall be considered for operation. The vision system shall provide a view of all operations and activities in the tank, end effector exchange module, and other applicable areas.

2.2.12.1 Cameras and Video Displays. Monoscopic color vision will be provided by at least three pan/tilt/zoom cameras positioned to give a general tank overview. The cameras will have a 10:1 zoom capability, low light sensitivity down to 0.1 lux, and will be radiation shielded or hardened to 
operate in the tank environment. A camera recording unit and video printer will also included as part of the monoscopic vision system.

Consideration shall be given to stereoscopic cameras mounted on the WRM near the end effector interface plate. This stereo vision system could be used to control the end effector and dexterous manipulator in the teleoperated mode. The cameras should also have the capability to automatically track the end effector.

2.2.12.2 Lighting. Lights will be provided as part of the system to illuminate the work area. They will be provided with adjustable intensity and capability to pan and tilt in unison with the cameras. Lights used with the stereo system will also have the capability to automatically follow the end effector.

\subsubsection{Decontamination}

Operation of the TWRS will result in contamination of the deployment mast, manipulator, cameras, lighting, and air conveyance system because these systems will be in direct contact with the waste being retrieved. Waste will be conveyed from tank C-106 to the accumulation tank by the air conveyance system, so any leak in the air conveyance system (e.g., hose, pumps, and tanks) may result in spread of contamination to the air conveyance module. To facilitate worker safety, equipment must be decontaminated before maintenance operations are performed. Therefore, to minimize contamination of the end effector exchange module and other equipment following in-tank operations, the deployment mast, WRM, and end effector will be remotely decontaminated to remove the majority of residual waste and contaminants as the deployment mast/WRM is withdrawn into the support mast (see Section 2.2.8). 


\section{SYSTEM ATTRIBUTES}

\subsection{General}

To help meet the requirements and challenges of the tank environment, the TWRS, as a whole, should have the attributes described in the following sections.

\subsubsection{Reliability}

The system should have a reliability factor of 0.9 (mean time between failure/mean time between failure + mean time for repair) with $95 \%$ confidence.

\subsubsection{Single Failure}

The system should not have any single failure points that could result in damage to the TWRS, storage tanks, or result in a release of the tank waste/environment to the environment.

\subsubsection{Explosion Protection}

All the components exposed to the tank environment shall be explosion proof and shall not provide an ignition source during tank operations.

\subsubsection{Interlocks}

The system shall have interlocks and safety features to ensure that the system shall not damage itself during operation.

\subsubsection{Assembly and Setup Time}

The system shall have an assembly and setup time of less then 80 hours. To facilitate the setup, assembly and eventual disassembly of the system, modular components, and assemblies should be created and used. These modular assemblies should meet transportation and lifting requirements using standard equipment.

\subsubsection{Connectors}

Connectors shall be used between the major systems, components, sections, and assemblies.

\subsubsection{Common Components}

Where applicable, common components and assemblies shall be used in the design of the TWRS. 


\subsubsection{Design and Operating Life}

The system shall be designed to operate 24 hours a day for 6 months without repair or changeout of systems or components. The design life of the system shall be 6 years with a minimum 2-year design life for individual components.

\subsubsection{Internal Environmental Exposure}

Components within the tank shall be designed for exposure to the environment given below.

3.1.9.1 Ambient In-Tank Temperature. The TWRS and deployment system shall be designed and constructed to function within an ambient temperature range from +50 to $+150^{\circ} \mathrm{F}$.

3.1.9.2 Relative In-Tank Humidity. The TWRS and deployment system shall be designed and constructed to function within a humidity range from 10 to $100 \%$.

3.1.9.3 In-Tonk Pressure. The TWRS and deployment system shall be designed and constructed to function within a pressure range of \pm 10 in. of water.

3.1.9.4 In-Tank Dust. The TWRS and deployment system shall be designed and constructed to function within an environment that contains an abrasive dust in the tank vapor space.

3.1.9.5 In-Tank Chemical Environment. The TWRS and deployment system shall be designed and constructed to function in a chemical environment that varies from concentrated nitric acid fumes to waste material with a pH approaching 14 .

3.1.9.6 In-Tank Radiation. All in-tank components shall be capable of withstanding a dose rate of $2,00 \mathrm{Rad} /$ hour with an accumulated dose of $1 \times 10^{8} \mathrm{Rad}$ minimum. Minor equipment changeouts, at intervals of not less than 6 months, may be used to obtain this design life. The maximum exposure to radiation over a 6-month period shall not exceed $1 \times 10^{6} \mathrm{Rad}$.

\subsubsection{External Environment}

Components located external to the tank shall withstand the natural environment given below following sections.

3.1.10.1 Ambient Temperature. System components shall be designed and constructed to function in external temperatures that range from -20 to $120^{\circ} \mathrm{F}$.

3.1.10.2 Relative Humidity. System components shall be designed and constructed to function in external humidity environments that range from 4 to $100 \%$.

3.1.10.3 Wind Speed. The TWRS shall be able to operate under wind speeds up to $40 \mathrm{mph}$. In addition, the "WRS shall be able to withstand, without damage, wind speeds up to $80 \mathrm{mph}$. 
3.1.10.4 Moisture. System components shall be designed and constructed to function in external rain environments with rainfalls at the rate of up to 2 in./hour. System must also be able to function in periodic external snow environments with snowfall accumulations of $2 \mathrm{ft}$.

3.1.10.5 Dust. System components shall be designed and constructed to function in an environment that has periodically has severe dust storms.

3.1.10.6 Exposure. System components shall be designed and constructed to function in an environment of direct exposure to sunlight. Components shall not overheat or degrade due ', direct exposure to sunlight.

\subsubsection{Contamination Protection}

The components and assemblies of the TWRS shall incorporate attributes that will minimize the possibility of the system becoming contaminated. These attributes will also facilitate the cleaning of the TWRS system. Some of these attributes are smooth surfaces; no unnecessary holes, slots, cracks or crevices; no protruding or odd configurations; and materials or coatings that allow cleaning and decontamination. Cleaning shall be with a $\mathrm{CO}_{2}$ cleaning system, steam, or 6 molar nitric acid.

\subsubsection{Storage}

The TWRS will be placed in long-term storage between tank operations. The temperature may be as low as $-20^{\circ} \mathrm{F}$ in the winter to as high as $150^{\circ} \mathrm{F}$ in the summer. To the maximum extent practicable, all TWRS components shall be capable of withstanding these conditions, or alternative provisions must be made. Alternative provisions may include localized environmental conditioning at the specific component or temporary removal of the component for separate storage.

\subsubsection{Materials Exposed to Waste}

Those systems that are exposed to the tank environment and waste should be constructed of materials that will not degrade due to the exposure. Those components that will degrade in the tank environment shall be housed with appropriate seals and shielding. Those components that are not directly in contact with the tank environment shall be coated to allow cleanup and decontamination of the equipment.

\subsection{Equipment Description}

\subsubsection{Bridge}

The bridge shall be designed with the specific features described in the following section to facilitate ease of assembly, operation, maintenance, decontamination, and removal.

3.2.1.1 Leveling. A mechanism, such as screw jacks, that will allow the system to be leveled to compensate for any irregularities in the foundations shall be located at appropriate locations on the bridge. The system shall allow leveling even after the TWRS has been assembled and installed without disassembly of any components of the TWRS. 
3.2.1.2 Assembly/Disassembly. The system shall be designed as modular as possible. Components of the system shall use alignment pins, attachment points that can be secured with minimal equipment, captive bolts and nuts where applicable, and other devices that will help simplify the assembly and disassembly the system.

3.2.1.3 Decontamination. This system will not be intentionally exposed to the tank environment tut should be designed and fabricated to minimize decontamination if required. The attributes adding in decontamination are covered in Section 2.2.11, and materials requirements are covered in Section 2.2.13.

\subsubsection{Tower/Mast}

3.2.2.1 Support Tower. The support tower system shall also meet the requirements of mrodularity, assembly, and decontamination described in Section 3.2.1.

3.2.2.2 Support Mast. The support mast shall provide environmental containment of the retrieval system during disassembly and/or transportation of the system to another tank or a decontamination facility for in-depth maintenance or decontamination. To facilitate containment, knife valves shall be provided at the bottom of the support mast, and services (e.g., cables and hoses) shall pass through the mast via bulk head connectors. A filter may be used in the support mast housing to ensure that the mast is maintained at atmospheric pressure. The support mast shall also be designed to withstand the worst case operating conditions of the HVAC system, tank environment, and storage conditions.

The system shall have a lifting arrangement integrated into the system and shall be constructed of materials that will withstand the tank environment and decontamination.

\subsubsection{Waste Retrieval Deployment System}

3.2.3.1 Deployment Mast. The deployment mast shall provide the structural support and alignment features for the operation of the WRM.

- Speed and Accuracy-The deployment mast shall have a maximum operating speed of $15 \mathrm{in} . / \mathrm{sec}$ with incremental speed variability from 0 to 15 in a minimum of 15 increments. The system shall have a positional accuracy of $\pm 1 / 2$ with incremental jog capability.

- Failure Protection-The deployment mast shall be fail safe. It shall have a hard stop to ensure that the system cannot fall if the deployment mast drive mechanism fails. It shall also have a brake that will allow the system to be locked in a position, but this locking mechanism shall allow manual release and retraction under all accident scenarios.

- Materials/Sharp Edges-The deployment mast should fabricated from materials that will be unaffected by the tank environment and decontamination. The system shall also incorporate attributes to allow the system to be sleeved. These attributes include no sharp corners, odd configurations, projecting components, and mounting areas to attach the sleeve. 
- Contamination Traps-The system shall also include the features and attributes that will simplify and minimize contamination traps. The attributes of decontamination are described in Section 2.2.11. The sealed and closed to minimize the tank environment being funneled from the tank.

3.2.3.2 Waste Retrieval Manipulator. The WRM shall position the end effector within the tank.

- Failure Protection--The WRM shall be fail safe, and the system shall have hard stops and power monitoring to prevent the WRM from damaging itself during operation. It shall have brakes that allow the system to be locked in a position but still permit manual release under all accident scenarios. The system shall have the ability to come to a vertical orientation during a accident recovery scenario for removal from the tank.

- Force and Torque Sensing-The WRM shall have force and torque sensing at the end effector interface plate and interface between the WRM and deployment mast. This information shall be displayed at the SCC.

- $\quad$ Position Tracking-The WRM shall have position tracking (resolvers) for each joint. The tracking mechanism shall track the full range of WRM motion and shall not be affected by power loss or WRM shut down.

- Positional Accuracy-The WRM shall have positional accuracy of $\pm 1 / 2$ with incremental jog capability. Each joint shall have a maximum operating speed of 15 in./sec with incremental speed variability from 0 to 15 in a minimum of 15 increments. The control system shall permit individual joint movements as well as computer-controlled movements described in the control section.

- Cameras-Cameras shall be mounted around the WRM so that under any configuration or movement every part of the manipulator can be seen by a camera.

- Surface Smoothness-All exterior surfaces shall be smooth for ease of decontamination. Conical, radiused, or chamfered surfaces shall be provided as required to eliminate "hangups" during insertion and removal through the waste tank riser.

- Sharp Edges-The WRM shall be free of sharp corners, odd configurations, and projecting components that could catch or snag a protective sleeve.

- Brakes-During operation, it may be necessary to maintain a desired position for an extended period of time and to have the WRM remain as stable as possible. To provide this capability, each actuator or joint shall have a brake incorporated that can be locked to maintain position. The brakes on the arm shall require power to activate, but the brakes on the vertical positioning mast shall activate with a loss of power. The TWRS shall not experience motions greater than 0.25 in. at the end effector interface plate for a period of 30 minutes after the TWRS and vertical-positioning systems have been locked and have come to rest. In addition, dynamic braking shall be incorporated so the TWRS will gradually droop to the vertical position in the event of power loss to facilitate manual 
recovery from the tank in the event of failure. The operator shall have the capability to override the dynamic braking. Failure of the control system shall not affect operation of the brakes. The TWRS brake system shall be designed to be fail safe and recoverable.

- Utilities-The following utilities shall be provided at the end of the WRM:

- Two hydraulic services (one sending and one receiving) with a minimum working capacity $170 \mathrm{~L} / \mathrm{min}$ at $13 \mathrm{MPa}$

- Two hydraulic services (one sending and one receiving) with a minimum working capacity $7 \mathrm{~L} / \mathrm{min}$ at $37 \mathrm{MPa}$

- One pneumatic connector: $0.09 \mathrm{~m}^{3} / \mathrm{s}$ at $1.4 \mathrm{MPa}$

- One 20-cm diameter vacuum service: $76 \mathrm{~m}^{3} / \mathrm{s}$ at $60 \mathrm{KPa}$

- One high-pressure water service: $22.71 \mathrm{~L} / \mathrm{min}$ at $380,000 \mathrm{KPa}$

- $\quad$ One low-pressure water service: $30.3 \mathrm{~L} / \mathrm{min}$ at $551.6 \mathrm{KPa}$.

Note: The hydraulic, pneumatic, and fluid connections shall be self-sealing with no leak valves. During the connection and disconnection of the EEIM, the pressures shall be zero except for residual head in the lines

- One direct current (dc) power supply. Thirty twisted pair (for a total of 60 wires), individually shielded, AWG 22 sized wires (suitable for $50 \mathrm{Vdc}$ ).

- Four shielded triplets (for a total of 12 wires) of AWG 16 sized power wires [suitable for $110 \mathrm{~V}$ alternating current $(\mathrm{ac})]$.

- Two RG-59U cables of 75 ohm impedance, shielded, low noise and two RG-174 cables of $50 \mathrm{ohm}$ impedance, shielded, low noise.

Note: All electrical shiclds shall be isolated from ground including coaxial lines.

- One flexible conduit 0.5 -in. inside diameter to provide for routing of additional utilities.

For easy decontamination of the arm, all of the above listed utilities shall be routed internally through the arm/mast/deployment system. The conduit line shall be sealed at the mating surface of the end effector exchange plate.

\subsubsection{End Effector Interface Mechanism}

The EEIM shall have features that seal the connection points of the services in the EEIM from the tank environment and also allow the alignment of the two EEIM sections for remote attachment. The EEIM shall support the sleeving system that will be used on the arm. The EEIM shall be fail 
safe with redundant systems. No single failure, operator or system, shall allow the EEIM to drop the end effector. The EEIM shall provide a latching mechanism with the following capabilities:

- The EEIM shall provide a latching mechanism to draw and hold the mating surfaces together. The draw distance shall be determined by the distance to mate the electrical and fluid connectors and set the peripheral seal.

- Sufficient force shall be produced by the latching mechanism to overcome tha connector mating forces, seal compression forces, and force required to prevent separation of the mating plates during application of moment and other forces on the interface plates.

- The EEIM shall be capable of forcing apart the two halves during the demating operation.

- The latching mechanism shall require positive application of energy to disengage the latch.

- During deployment of the arm in a tank, the latching mechanism shall be able to maintain positive grip on the end effector during subsequent recovery operations of the TWRS, including incidental contact of the end effector with the tank, riser of waste.

- There shall be no single mode failure mechanism that would cause the end effector to be released into the waste tank.

- There shall be no single mode failure that would cause the EEIM halves to separate, which would expose electrical or fluid connectors as spark or leak sources in the waste tank environment.

- In the event of a power failure to the latching mechanism, a manual release feature shall be included as part of the latch design.

- The EEIM shall include alignment features to ensure the accurate mate of the system but will prevent damage to the systems during engagement.

- The EEIM shall include the following seal features:

- Seals shall be provided near the circumference of the EEIM. A seal shall be provided to seal the EEIM mating halves and seal the EEIM to the TWRS wrist and to each end effector. The seals shall be designed to prevent the intrusion of contamination from the tank contents and decontamination materials that could damage the utility and latching connections.

- Each utility that passes through the EEIM shall be sealed to prevent intrusion of the tank atmosphere in between the EEIM mating surfaces and into the interior of the arm. 


\subsubsection{End Effector}

The only end effector identified at this time is the waste dislodging system. The end effector shall use high-pressure, low-volume water jets to dislodge and break up the waste in preparation for retrieval with the air conveyance system. The jets shall be mounted inside a shroud to reduce splashing and direct the water flow. The end effector shall be fitted with one of two mating interface plates for hookup to the EEIM to incorporate connectors for the high-pressure water, hydraulics, pneumatics, electrical, and other required utilities. It shall also be capable of transferring loads to the WRM through the EEIM. Another separate remote coupling system shall be provided for the air conveyance hose. Other end effectors will be used as applicable.

\subsubsection{End Effector Exchange Module}

3.2.6.1 Contamination Containment. The end effector exchange module shall be a contamination containment module and use bulk head connectors, sliding knife valves at the access points, self-sealing quick disconnects, and other attributes to ensure that the end effector exchange module environment can be isolated and contained. It is recommended that this unit be configured like a cargo container with lifting points at the four corners and fork lift ports in addition to the attributes listed.

3.2.6.2 Heating, Ventilating, and Air Conditioning. The HVAC system shall draw air from the end effector exchange module, into the tank and out of the filtered exhaust system. To facilitate this, the end effector exchange module shall have an inlet location, preferably at the top of the unit. Air shall enter the end effector exchange module at a rate of approximately 200 SCFM. A nuclear grade HEPA filter, preceded by a $30 \%$ ASHRAE prefilter, shall be at the air inlet to protect against backflow. An electric heater is required in the air inlet to maintain air temperature above $40^{\circ} \mathrm{F}$, protecting the filters from freezing. The filter housing shall be side access, bag-in/bag-out style. Many of the ventilation system functions may be provided by the same equipment used to exhaust the $\mathrm{CO}_{2}$ effluent from the decontamination process. This equipment shall be located external to, but attached to, the end effector exchange module. Two pair of pressure sensors (1/2 in. NPT mounted) shall be provided that are suitable for the connection of a differential pressure instrument capable of providing a signal and pressure reading at the TWRS control console. One pair of sensors shall be across the inlet prefilter, and the other pair shall be across the HEPA filter. Inside the end effector exchange module, a thermostat shall regulate the inlet heater, quick disconnect connections for manual decontamination nozzles, waste load isolation chamber, and glove ports for maintenance and servicing components of the TWRS. The interior of the end effector exchange module shall be completely lined with stainless steel. This lining shall have sealed joint to ensure containment of all moisture, decontamination chemicals, and tank wastes. The end effector exchange module shall be capable of having shielding mounted on its outer walls.

3.2.6.3 Cameras. The end effector exchange module shall have environmentally protected cameras with pan and tilt capability mounted to allow remote viewing of all areas of the end effector exchange module.

3.2.6.4 Remote Bagging Capability. The module shall be capable of remotely bagging or packaging any contaminated end effectors, deployment mast components, or other internally 
contained module components from the enclosure (including the decontamination system and end effector exchange module).

3.2.6.5 Electrical Outlets. At least two $110 \mathrm{Vac}, 60 \mathrm{~Hz}, 20 \mathrm{amp}$ conventional grounded, duplex electrical outlets shall be provided (one at each end of the inside of the enclosure) to use electrically operated tools or lights. These outlets are not to be used for permanent electrical connections.

3.2.6.6 Surface Smoothness. The end effector exchange module shall be designed and fabricated to facilitate cleaning of contaminated surfaces. Design shall incorporate smooth surfaces and sealed connections for ease in decontamination. Joints or access areas with exposed crevic:s (contamination traps) may be covered with a temporary cover. Exposed surfaces of machined components, sheet metal, or structural elements within the end effector exchange module enclosure, shall have a surface finish of 32 RMS or better.

3.2.6.7 Maintainability. The end effector exchange module enclosure shall be designed so the components that are most likely to fail and or components that require more frequent service are easily replaced as a unit or as a subassembly. Equipment contained within the enclosure shall be modular in design to facilitate fast repair cycles. All components contained within the enclosure shall be maintainable by a person working through the glove-ports.

\subsubsection{Air Conveyance System}

All systems and aspects of the air conveyance system that contain or move the tank wastes and environment shall be double contained, have remote connections, remote filter change outs, and other aspects to allow the system to be handled remotely.

3.2.7.1 Air Conveyance Module. All the equipment located within the air conveyance module shall have lifting attachments and configurations to allow removal of the equipment. The modules shall be capable of being sealed remotely to provide containment of the hazardous materials contained in them.

3.2.7.2 Air Conveyance Hose. The air conveyance hose shall attach to the mating ends by a connection that can be remotely disconnected. Each length of hose shall be attached to the WRM with sufficient slack to allow rotation of each manipulator joint. The hose attachment devise on the manipulator must rotate and move along the length of each WRM section to facilitate extension and compression of the hose. At appropriate locations, the system shall have decontamination hoses to allow the system to cleaned and flushed.

3.2.7.3 Air Conveyance Heating, Ventilating, and Air Conditioning. The air conveyance HVAC system may be an integral part of the TWRS ventilation system.

\subsubsection{Tank/Structure Interface}

The tank/structure interface shall provide containment with no loads transmitted to the top of the tank. This coupling between the tank and bridge shall interface with tank riser. The upper end of this adapter shall seal against the underside of an enclosure located underneath the bridge. This 
enclosure shall also be equipped with decontamination equipment for removal of residual waste and contaminants adhered to the surface of in-tank equipment. The operations shall be performed remotely and viewed by a TV camera located within the housing.

\subsubsection{Utilities Module}

The utilities module shall house equipment required for manipulator operation including a demineralizer; intensifiers for the end effector water jets; hydraulic motors and power units; and a local control center for manual operation of the WRM. Demineralized water shall be provided to the high-pressure water jet nozzles to prevent plugging. Equipment shall be grouped with adequate space for maintenance activities. As with other systems and components of the TWRS, it is recommended that this module also be configured like a cargo container with lifting points, fork lift ports, and cargo doors.

\subsubsection{Heating, Ventilating, and Air Conditioning}

The HVAC system shall control the tank environment and confinement of waste by controlling the atmospheric pressure inside the tank, end effector exchange module, and support mast by maintaining a constant flow of air from the support mast through the end effector exchange module into the tank. The tank HVAC system shall tie into existing tank risers for exhaust and intake air.

\subsubsection{Control System}

The TWRS shall have two control systems: the end effector exchange module control system and SCC.

3.2.11.1 Speed Control. The TWRS shall provide the operator with infinitely variable speed control. During any movement, no part of the arm shall exceed $10 \mathrm{in} . / \mathrm{second}$. In addition, the maximum speed of the arm shall not be less than 5 in./second.

3.2.11.2 Protective Interlocks. The control system shall provide protective interlocks to prevent equipment damage and personal injury from improper operation. The control system shall also ensure that all TWRS operations do not result in the erratic system operation.

3.2.11.3 System Flexibility. Flexibility and variability of the operating environment parameters should be imbedded in the control system to allow all operations, software modifications or calibrations, and commands to be implemented without secondary systems. Variable soft stops and/or boundaries for each joint and tank environment shall be included in the control architecture.

3.2.11.4 Supervisory Controller. The control architecture of the SCC shall be a 3-D graphical system with joint by joint control, previewed path planning and implementation, and coordinated motion. Communications for command and data between the SCC and subsystems shall be accomplished using an Ethernet system. All aspects of the activities and systems functioning in the waste conveyance operation shall be monitored from the SSC.

3.2.11.5 Model Generation/Update System. The SSC control system shall provide the positional information for each joint of the arm and deployment mast. All axes shall incorporate 
absolute position feedback so that homing is not required, and the position is known after recovery from a power failure. The update rate on the feedback shall be a minimum of $30 \mathrm{~Hz}$. The control system shall provide either discrete or continuous position indication for the deployment system and the end effector exchange module according to the nature of the component being instrumented and its function in the operation of the system. All discrete operating positions shall be instrumented (for example, both "open" and "closed" positions of two-way valves).

The TWRS shall have emergency stop buttons that shall stop all motion of the TWRS (including mast, arm, deployment, and end effector operations) without damaging any components or control systems and without allowing a release of any hazardous materials. The emergency stop shall instantly interrupt the controller to disable all actuators while applying all brakes. The soft stop signal shall provide a rapid, but controlled stop, and shall interrupt the controller to quickly decelerate all actuators to zero velocity. An emergency stop button shall be provided at the TWRS console and at each local control panel/pendant. The emergency and soft stops shall not reset nor disable the control system. The control system shall provide connections for external actuation of the hard and soft stop. These external connections shall use low voltage dc (12 or $24 \mathrm{~V}$ ) and shall tolerate cable runs of size AWG 22 conductors of up to $100 \mathrm{ft}$. The external emergency stop circuit shall be normally closed and shall be actuated by being opened. The soft stop circuit shall be normally open and shall be actuated by being closed. Provisions shall be made for external connections to buyer's equipment at both the tank and operations control trailer.

A means shall be provided to ensure that the control system shall not accept commands or control inputs from more than one point-of-control at a time. This is a safety feature to prevent equipment damage or danger to individuals who are trying to control the equipment at the same time from different places. For local panels/pendants, a means shall be provided for the operators to ensure that point-of-control cannot be taken away without their knowledge or permission. The control system shall indicate which point-of-control is currently active and shall indicate at each point-of-control whether it is currently active. Failure of the currently active point-of-control shall not prevent switching to another point-of-control. Display functions of consoles, panels, or pendants shall not be affected by point-of-control switching.

3.2.11.6 Power Supply. The TWRS shall be powered from a three-phase, $480 \mathrm{~V}$ supply for the TWRS controller and hydraulic power unit. The controller shall include a built in uninterruptable power supply (UPS) rated for limited operation.

\subsubsection{Camera and Lighting}

The operator vision system used to assist in the control and monitoring of the waste retrieval process shall consist of cameras, video displays, and lights. Both helmet-mounted and panel-mounted displays shall be provided for operation.

3.2.12.1 Cameras and Video Displays. Pan/tilt/zoom cameras shall be provided and positioned to provide a general tank overview. The cameras shall be radiation shielded or hardened to operate in the tank environment. A camera recording unit and video printer shall also be included as part of the monoscopic vision system. 
Depth perception shall be provided to the operator by a pair of stereoscopic cameras mounted on the WRM near the end effector interface plate. This stereo vision system shall be used to control the end effector and dexterous manipulator in the teleoperated mode. The cameras shall have the capability to automatically track the end effector.

3.2.12.2 Lighting. Lights shall be provided adjacent to each camera to illuminate the work area. They shall be provided with adjustable intensity and capability to pan and tilt in unison with the cameras. Lights used with the stereo system shall also have the capability to automatically follow the end effector.

\subsubsection{Decontamination}

To minimize contamination of the end effector exchange module and other equipment following in-tank operations, the deployment mast, WRM, and end effector shall be washed down to remove the majority of residual waste and contaminants as the deployment mast/WRM is withdrawn into the support mast. The end effector, deployment mast, and WRM will be constructed of materials, such as stainless steel, that are capable of resisting the harsh in-tank environment and are readily decontaminable with $\mathrm{CO}_{2}$, high-pressure water and chemicals. A decontamination ring shall be located in the tank interface structure. Remote access to the decontamination ring shall be considered in the structures and end effector exchange module design. The components of the decontamination ring shall be remotely replaceable.

The end effector exchange module shall have ports and $\mathrm{CO}_{2}$ service supplies to allow manual decontamination. The service supplies and ports shall be dispersed throughout the end effector exchange module to meet the decontamination requirements.

During normal TWRS decontamination operations, the atmosphere in the decontamination portion of the enclosure will be $\mathrm{CO}_{2}$ at a pressure of -0.3 to -1.0 in. of water. $\mathrm{CO}_{2}$ pellets shall be used for decontamination of the end effectors and mast comporients as follows:

- Pellet size $\quad 1 / 8$ in. diameter $\times 1 / 4$ in. long

- Pcllet density $\quad 1.56 \mathrm{~g} / \mathrm{cm}^{3}$

- Pellet velocity 75 to $1,000 \mathrm{ft} / \mathrm{second}$

- Flow rate 450 SCFM at 250 psi.

Chemicals that may occasionally be applied internally to the confinement enclosure and equipment contained inside the enclosure, or TWRS components, require manual decontamination:

- Water spray

- 3 to 6 molar nitric acid

- $\quad 3$ to 6 molar oxalic acid 
- $\quad$ Turco Cleaning Compound 4502

- $\mathrm{CO}_{2}$ pellets directed under pressure of $250 \mathrm{psi}$.

\subsection{Safety Requirements}

\subsubsection{Personnel Safety}

All equipment shall be designed and configured for the safety of maintenance personnel and operators. Specifically, the following safety-related items shall be provided: (a) chassis, arm, and end effectors grounding to prevent electrical shock, (b) avoidance of sharp edges and corners, (c) adequate visibility of signs, labels and warnings, and (d) avoidance of the possibility of overturning or tilting. Applicable portions of the National Electric Code (NEC) shall be used in the design and manufacturing of the equipment to be furnished.

\subsubsection{Explosive Environment Protection}

All in-tank equipment shall be qualified safe for use in environments containing flammable gases, specifically hydrogen. The in-tank equipment shall meet the requirements for qualification under the NEC for Class I, Division I, Group B components.

\subsubsection{Equipment Protection}

Safety features such as limit switches, shock absorbers, overload clutches, and lightning rod(s) shall be included to prevent damage to the equipment. All load-bearing components shall be designed with the specificized safety factors.

\subsubsection{Special End Effector Exchange Module Safety Considerations}

3.3.4.1 Fire. Fire external to the enclosure shall be handled in accordance with standard emergency procedures and equipment already in place at Hanford for such applications.

Fire extinguisher ports shall be provided in the enclosure, on each side of the isolation door. These ports shall permit fire extinguishers, modified to fit the ports, to be used to extinguish the fire. Suggested port configurations are as shown on drawing H-4-109281 in Wallace (1993).

3.3.4.2 Port Protection. The ports of the enclosure shall include a feature that shall ensure that gloves, bags, or any other items shall not protrude, or be sucked into, the enclosure where they could be torn or damaged by moving equipment during automated operations. All enclosure openings shall have covers that can withstand the pressures that may be developed within the system.

3.3.4.3 Restricted Materials. In general, the following restricted methods and materials shall not be used:

- Hydraulically actuated equipment that require organic hydraulic fluids 
- Any flammable materials

- Teflon, nylon, or other materials subject to radiation damage at relatively low exposure, shall not be used on system that will be exposed to the tank waste/environment.

3.3.4.4 Proof Testing. The enclosure shall be pressure tested to the worst case operating condition that the HVAC system and tank could develop without any evidence of structural failure or permanent distortion.

\subsection{Documentation}

Parts lists and manuals shall be provided by the seller to the buyer as described in the purchase order. Parts lists and manuals should include, but not be limited to, those described below.

\subsubsection{Parts Lists}

The seller shall provide a list of recommended spare parts. The list shall contain drawings of unique parts and the delivery time after receipt of an order.

\subsubsection{Maintenance Manual}

The maintenance manuals shall contain a section listing the purposed maintenance schedule on all components. For all components listed in the maintenance schedule, the following shall be detailed: (a) complete maintenance information regarding the tear-down, if applicable, (b) servicing procedures, (c) servicing tools, (d) replacement parts, (e) listing serial numbers, and (f) replacement fluids. The maintenance manual shall contain a trouble-shooting section listing projected failure modes, steps to identify cause of failure, and steps to resolve failure.

\subsubsection{Operating Manual}

The operating manual shall contain a section listing all operating, maintenance, and performance specification information that is supplied by the manufacturer of serial numbered components. The operating manual shall contain all the information to control and operate the TWRS. The operating manual shall be reviewed and approved by the buyer prior to acceptance.

\subsubsection{Software Manual}

The software manual shall contain sections providing the following: (a) full code listings, (b) user's instructions, (c) test and installation procedures, and (d) any other information needed to fully test and use all capabilities of the software. 


\section{MAINTENANCE REQUIREMENTS}

\subsection{General}

Because of the contamination of the waste currently in tank C-106, it is important that all in-tank equipment be Rad hardened, safe, and reliable. Assurance must be provided by the designer that all in-tank equipment has been analyzed for potential failure modes and is capable of successful recovery.

The size, weight, and expected contamination levels of the support mast/deployment mast/WRM ccmponents dictate that design features be incorporated to ensure capability for in-place visual examination and maintenance. Provisions must be also be provided in the design of these components to ensure that they can be separated and removed from each other for onsite maintenance. Features and methods must allow the WRM to be separated from the deployment mast, retracted into a container, and transferred to an onsite maintenance facility. At this time, there are no general purpose maintenance facilities available at the tank farms, so maintenance is generally performed in the field using a tent or "greenhouse," protective clothing, and breathing air as required. Depending on contamination and radioactivity level, the tent may have an HVAC system to filter the exhaust air. Because of the high costs associated with handling and transportation of radioactively contaminated materials, the use of a temporary tent facility is appealing; however, berause of the potential for the spread of contamination, soundness of the structure to withstand normally expected climatic conditions must be ensured. Hence, consideration should be given to use of a mobile maintenance van. Although Brown recommended against the use of a maintenance glovebox, a devise of this type may be necessary to disassemble the deployment mast/WRM into manageable sizes and lengths.

All driver equipment (such as motors, compressors, and hydraulic pumps) should be located exterior to the support mast containment to facilitate repair and/or replacement.

All load-bearing components shall be designed with a 5:1 safety factor for lifting points over the ultimate strength (breaking strength), or a 3:1 safety factor over manufacturer's yield strength of load bearing or lifting materials or components, whichever results in the most conservative safety factor. For normal condition design, allowable stresses for steel shall be in accordance with the American Institute of Steel Construction Manual of Steel Construction. For ductile materials other than steel, a safety factor of 3 shall be applied to yield. Brittle materials shall not be used as structural members, nor shall any window material be used as structural members.

All structural materials shall be in accordance with American Society of Testing and Materials or American Society of Mechanical Engineers standards. In-tank components shall be constructed of materials resistant to the tank environment and qualified as spark resistant as much as practical to minimize the use of coatings. Suggested materials include, but are not restricted to, austenitic stainless steel or titanium alloys that have been stress relieved.

The system shall be designed to minimize scheduled preventative maintenance. Components shall be selected or substituted where possible to reduce maintenance and increase mean time between failure. All required service shall be indicated on the service chart in the operation and 
maintenance manual. No components shall require service in intervals less than every 6 months. Tags and/or notices shall be attached to warn against operation before servicing after shipment.

The system shall be designed and fabricated to facilitate the cleaning of contaminated surfaces. Design shall incorporate smooth surfaces and sealed segments for ease in decontamination. The TWRS shall be readily adaptable to booting to aid in contamination control. Joints or access areas with exposed crevices (contamination traps) may be covered with a boot in addition to any sleeving that may later be used.

The system shall be designed so the components that are most likely to fail are readily accessible and easily replaced as a unit or as a subassembly. The system shall be modular in design to facilitate fast repair cycles. All in-tank components shall be maintained within the enclosure by a mechanic wearing anticontamination clothing and latex gloves.

Nonvolatile radiation resistant lubricants shall be used for in-tank components.

All subassemblies of the system shall be clearly identified in the operation and maintenance manual with descriptions of the components and/or subassemblies.

The seller supplied enclosures for electrical systems located outside the TWRS control trailer shall be NEMA Type 4 enclosures for outdoor locations that conform to NEMA ICS-6.

The system shall include detachable connectors at each motor/module to allow removal of a failed motor/module or cable. All electrical connectors shall be keyed to prevent mismating. These connectors shall also prevent unintended or inadvertent separation.

The system shall be designed so that a power surge, the loss of electrical power, or the return of lost power shall not result in hazardous motion of the system. The deployment mast shall be furnished with fail safe brakes (i.e., voltage off, brakes on). The TWRS actuators shall have dynamic braking with an override. In the event of a power loss, restart shall require a deliberate action by the operator.

The tank environment sevarely restricts the discharge of organic compounds during operation and all pussible failure modes. The maximum credible loss of fluid in an accident scenario shall be less than 5 gal.

Corrosion resistant materials shall be used where possible on components exposed to the in-tank environment; however, if coating of some components is required, it shall be capable of withstanding the tank environment, decontamination, and environmental conditions, and shall be Amercoat, ${ }^{a}$ or an approved equal. Those components that are to be painted shall be specifically identified.

a. Amercoat is a trademark of the American Paint Corporation. 


\subsection{Equipment Description}

\subsubsection{Bridge}

The bridge is not expected to require maintenance during its operating lifetime, but the surtem shall be designed to allow, as much as possible, remote assembly and disassembly.

\subsubsection{Tower/Mast}

4.2.2.1 Support Towor. The support tower is not expected to require maintenance during its operating life, but the system shall be designed to allow, as much as possible, remote assembly and disassembly.

4.2.2.2 Support Mast. The support mast is not expected to require maintenance during its operating life. However, since the deployment mast is retracted into the support mast, it would be advantageous to incorporate a maintenance module (working platform) at the top end of the support mast to permit "glove box" maintenance operation on the deployment mast (see Figure 4). For example, if the deployment mast or WRM are to removed from the support mast containment, the deployment mast/WRM must be secured to permit hoist system transfer. This maintenance module would also permit maintenance activities to be performed on the upper portions of the deployment mast. A manhole window and glove ports on the deployment mast would also permit visual examination and limited maintenance on the upper end of the WRM. Bag-in/bag-out techniques could then be used to remove either the WRM by itself or the deployment mast/WRM system from the support mast.

The support mast will have an intrical cable management system. This system is required to manage the cables and hoses that support the in tank activities. The cables management system shall not place undo stress, tensile and cyclic, on the service lines.

The support mast shall be constructed of materials that will be unaffected by the tank environment and decontamination.

\subsubsection{Waste Retrieval Deployment System}

4.2.3.1 Deployment Mast. As the deployment mast is retracted into the support mast, visual examination and remote access to the outside surface of the lower portion of the deployment mast is possible using the end effector exchange module. However, visual examination and maintenance on the upper portion of the deployment mast (including rotational actuator) is not possible without access through the support mast. In-depth maintenance operations on the internal portions of the deployment mast and on the WRM require that the loaded support mast be removed from the support tower and transferred to a maintenance facility for WRM removal and maintenance. Transfer of the support mast loaded with the deployment mast/WRM requires heavier equipment, detachment of the support mast from the tower, and a much larger facility for performance of maintenance activities. 


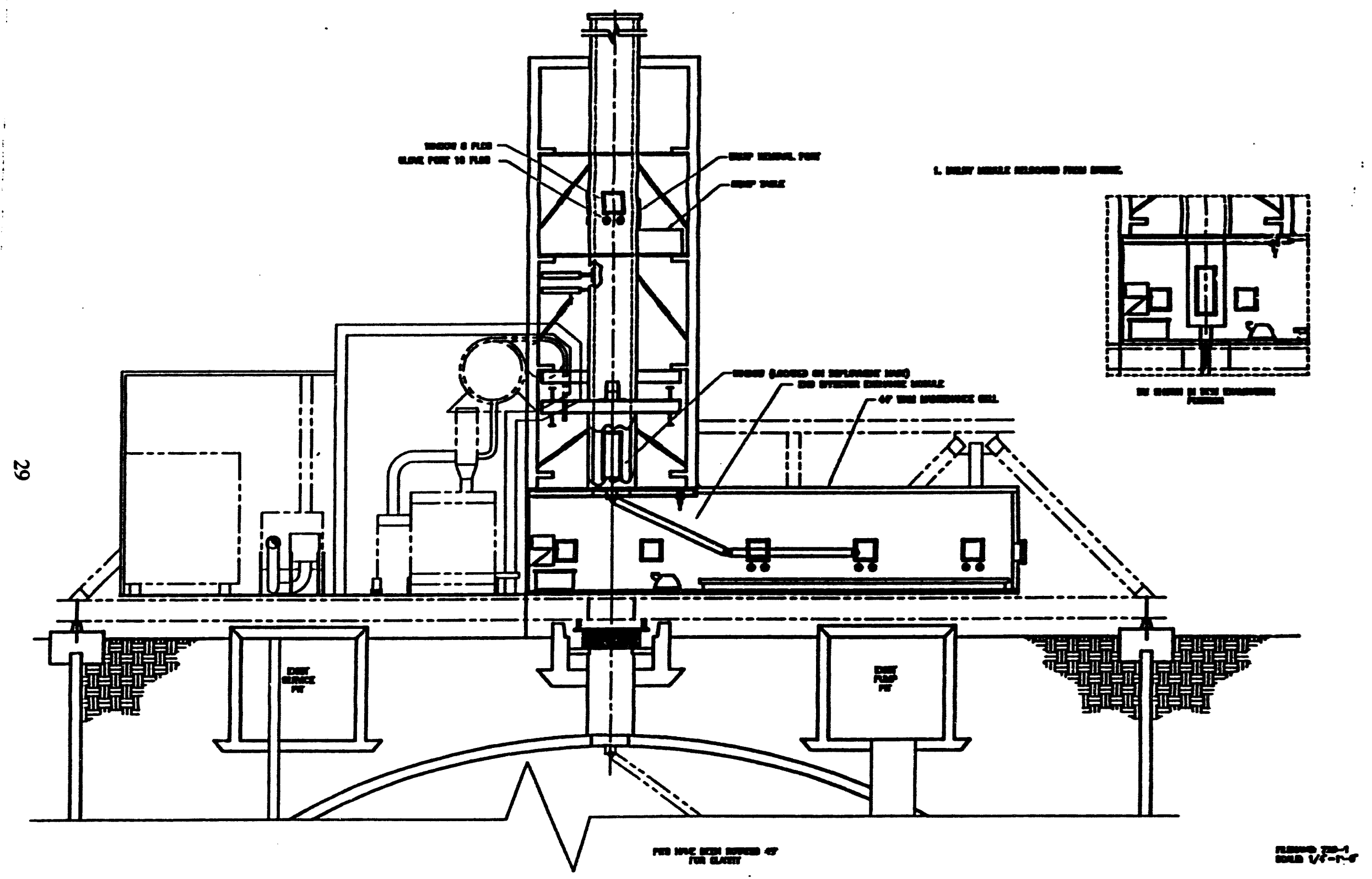

Figure 4. WRM maintenance cell concept sketch. 
A manhole access port located on the bottom end of the deployment mast (similar to that mentioned in Section 3.2.2) would permit visual examination and limited maintenance on the WRM (i.e., repair or replacement of hydraulic lines and actuators).

4.2.3.2 Waste Rotrieval Manipulator. No normal maintenance on the WRM is required to be performed in-tank. However, design features must be provided to ensure that the WRM can be retracted back into the deployment mast. For example, in the event of an actuator or hose failure, the arm must either return to the vertical position or some positive feature must be provided to return the arm to that (retractable) position. A manhole window on the lower end of the deployment mast may permit remote over ride of an actuator from the end effector exchange module.

Hydraulic hoses, fittings, high-pressure water line, electrical, and electronic lines are routed within the WRM, so they will not be accessible for maintenance without disassembly of the WRM. The hydraulic hoses may be disconnected at the end effector interface plate and withdrawn through the top of the WRM to permit disassembly of the manipulator arm; however, the high-pressure hose may present difficulty because it will not be as flexible.

Figure 4 depicts a horizontal WRM maintenance cell that permits glove-box type repairs to be performed on the WRM. After the WRM has been retracted back into the deployment mast, it could then be ejected outward, and the joints articulated to place the WRM in a horizontal position for maintenance operations. To incorporate this concept would require increased height of the end effector exchange module cell to permit rotation of the manipulator sections, each of which is approximately $12 \mathrm{ft}$ long, and relocation of the utility module to a location off the bridge.

- Hydraulic Drive Unit-The hydraulic drive unit required for actuator operation will be located within the utility module, so it will be accessible for maintenance and repair.

Over $75 \%$ of all hydraulic system failures are a direct result of fluid contamination, so the selection and proper use of filtration devices and use of "boots" are essential. Flexible boots mounted around piston rods serve to protect the rods from abrasion and prevent clearances and orifices from plugging and sticking. Filters should be located downstream from the system pump to ensure clean fluid to the actuators, and they should be located to provide unhindered access for replacement.

- Hydraulic Actuators-Hydraulic actuators required for manipulator operation are located on the WRM and must operate within the tank. Hence, they will not be accessible for maintenance and repair. They must be sized to preclude rod or cylinder damage from inadvertent overload, and seals must be selected to provide maximum design life. Rod clevis or connectors must be provided with features that permit actuator removal and replacement by remote means.

- Hydraulic Hoses-The hydraulic hoses required for actuator operation will be located within the WRM, so they will not be accessible for maintenance and repair. Therefore, strain relief and tie-down features must be provided to ensure increased reliability and preclude damage from hose bending, twisting, stretching, and rotation. Hose connections should incorporate remote operated quick-disconnect features to permit hose replacement by remote means. 
- Cables-The cables (electrical/electronic) required for WRM operation will be located within the WRM, so they will not be accessible for maintenance and repair. Therefore, strain relief and tie-down features must be provided to ensure increased reliability and preclude damage from bending, twisting, stretching, and rotation. Cable connections should incorporate remote operated quick-disconnect features to permit cable replaciment by remote means. All cables should be sealed inside the WRM housing to prevent exposure to the environment.

- High-pressure Hoses and Fittings-The high-pressure hoses and fittings required for end effector operation will be located within the WRM, so they will not be accessible for maintenance and repair. Therefore, strain relief and tie-down features must be provided to ensure increased reliability and preclude damage from bending, twisting, stretching, and rotation. Hose connections should incorporate design features that permit WRM joint rotation. Hoses should be sealed inside the WRM housing to prevent exposure to the environment. Extreme pressure hoses used by Tracor Hydronautics Inc. on their Cavijete, 20,000 psi, cavitating water jet system are comprised of a Delrin or Nylon II hose core, supported by six spiral wound layers of plated high strength steel wire, and covered with an extruded Nylon II cover. For this particular application, the hose's outside diameter is approximately two times the hose's inside diameter, minimum bend radii vary from 8 to $10 \mathrm{R}$, and minimum burst pressure varies from 52,000 to 58,000 psi for this 22,000 to 30,000 psi rated hose.

\subsubsection{End Effector Interface Mechanism}

Access to the EEIM is provided by the end effector exchange module. Design consideration must be given to remotely override the latch mechanism to ensure end effector disengagement from the manipulator arm. Caution must be exercised to ensure the high-pressure water line has been depressurized before unlatching the end effector from the EEIM.

\subsubsection{End Effector}

As a normal operation, the end effector will be removed from the WRM and replaced in the end effector exchange module using remote methods. The end effector will be spray rinsed to remove residual contamination and will then be disconnected from the air conveyance hose and manipulator interface plate. The end effector may then be removed from the end effector exchange module for further maintenance or repair.

\subsubsection{End Effector Exchange Module}

Since the height of the end effector exchange module (10 ft) is presently not compatible with the bridge and will probably be changed, consideration should be given to increasing the height to permit removal of a manipulator joint (approximately $12 \mathrm{ft}$ ). Equipment located within this module (hoist and handling tools) is accessible for minor maintenance by remote means. Major maintenance such as hoist removal will require manned entry under strict radiation controls. This would be feasible if the riser plug could be reinstalled and the $\mathrm{CO}_{2}$ system could be used to decontaminate the cell. 
Operating pressure within the enclosure shall be -0.3 to -1.0 in. of water.

A method of obtaining swipes for smearable evaluation of decontamination status of end effectors, TWRS deployment mast and other equipment, and the means to remove the swipes from the end effector exchsnge module shall be designed.

During normal TWRS deployment and operations the atmosphere within the enclosure will be air at 50 to $120^{\circ} \mathrm{F}$, at a pressure of -0.3 to -1.0 in. of water.

There should not be large quantities of waste material internal to the enclosure, as it is normally confined within the $\mathrm{CO}_{2}$ cleaning module. However, the waste material that may be expelled within the enclosure, if an unexpected event should occur, may have a pH approaching 14.

\subsubsection{Air Conveyance System}

4.2.7.1 Air Conveyance Module. Equipment located within the concrete portion of the air conveyance module (i.e., hose reel, cyclone separator, tank, and knock out drum) is not expected to require maintenance other than occasional flushing to prevent clogging. Valves fitted with reach rod handles could used to back up solenoid operated valves.

4.2.7.2 Air Conveyance Hose. Wallace (1993) indicated that routing the air conveyance hose into the tank through a peripheral riser may be a more effective design because it may lessen radiation exposure, reduce maintenance, and minimize hose requirements. However, further consideration of this concept must address the further complication of in-tank hook-up of the air conveyance hose to the end effector.

A section of the air conveyance hose vill be located on the WRM, so the lower end could be disconnected from the end effector by remote operation through the end effector exchange module. However, disassembly of the upper joint may be more difficult because the hose is attached along the entire length of the WRM and through the section that remains within the deployment mast. Details of the interface between the hose reel section and WRM hose section have not been provided, so the final design should consider features for hose removal. The hose on the reel located in the concrete portion of the air conveyance module will be contaminated because it is used to convey waste from the tank.

4.2.7.3 Air Conveyance Heating, Ventilating, and Air Conditioning. Equipment located within the steel portion of the air conveyance module (i.e., air heaters, fans, blowers, and coils) will be accessible for maintenance. This equipment is standard commercial equipment, therefore, operating and maintenance manuals should be provided by the supplier.

\subsubsection{Tank/Structure Interface}

The tank/structure interface is not expected to require maintenance over its anticipated life. Remote access to decontamination wash down/cleaning equipment located in this area is available through the end effector exchange module. However, this equipment is not expected to require maintenance during its operating life. Design features to provide remote removal and replacement of the spray ring and TV camera would ensure confident operation. 


\subsubsection{Utilities Module}

Unhindered access to equipment located within utilities module is possible because this equipment will not be subjected to radioactive contamination. However, grouping of the equipment with adequate space for maintenance activities requires a building too large for the bridge. Therefore, locating the utilities module off the bridge would facilitate maintenance activities and provide a safer and more adequate environment for manual operation of the WRM from the local control center. Equipment located within the utilities module consists of standard commercially supplied components, therefore, equipment operating and maintenance manuals should be provided with equipment.

All high-pressure hoses, fittings, and components must be shrouded to preclude injury or equipment damage resulting from equipment failure. High-pressure leaks will create jets, which can penetrate the body and introduce air into the bloodstream resulting in injury or possible fatality.

\subsubsection{Heating, Ventilating, and Air Conditioning}

Unhindered access to HVAC equipment located on the enclosure filter skid is possible since this equipment will not be subjected to radioactive contamination. Contaminated air from the tank exhaust riser is directed to the condenser skid, which is not designed for personnel entry. The exhaust air is then directed to the filter skid and then to the fan skid, both of which are designed for personnel entry. However, the exhaust duct and filters are expected to be radioactively contaminated, which will require shielding of these components and maintenance activities to be performed under strict radiation controls. Bag-in/bag-out methods must be developed for sampling and filter replacement. Equipment located on the various HVAC skids consists of standard vendor-supplied components; therefore, equipment operating and maintenance manuals should be provided with equipment.

\subsubsection{Control System}

Control system equipment includes standard commercial electronic equipment (e.g., computer workstation, controllers, motor drivers, and multichannel converters) located in areas that are accessible for hands on maintenance activities. Operations and maintenance manuals should be provided with this equipment.

4.2.11.1 Software Design. Because this system will he used in a mockup for equipment and procedure verification, changes to the system are anticipated. To aid in these changes, all system software shall be completely commented and documented, and the system source code shall be provided. All software shall be developed, tested, and documented according to Institute of Electrical and Electronic Engineers (IEEE) standards.

All components required to modify, update, or change nonpropriety portions of the control software shall be provided as part of the system.

4.2.11.2 Code. All code shall be written in $\mathrm{C}$ or $\mathrm{C}++$. All coding shall follow software quality assurance requirements as described in the IEEE standards. 
4.2.11.3 Code Validation. Software testing and test documentation shall follow software quality assurance requirements as described in the IEEE standards.

\subsubsection{Camera and Lighting}

4.2.12.1 Cameras and Video Displays. The cameras are capable of being deployed into tank C-106 through the 12-in. diameter risers and are not expected to require cooling for the retrieval process. They are removable to allow for maintenance or replacement and are protected from contamination by a waterproof covering.

Cameras will also be required for above tank remote activities, which will include decontamination and maintenance work inside the end effector exchange module and various areas on the mast where remote work or inspections will be preformed.

Video displays will be part of the control systems and will have unhindered access for repair or replacement.

4.2.12.2 Lighting. All lights shall be easily replaced with standard components. It may be desirable to have several lights at reduced wattage to reduce thermal heat and also to provide redundant light sources.

\subsubsection{Decontamination}

The end effector, deployment mast, and WRM will be constructed of materials, such as stainless steel, that will resist the tank environment and to facilitate decontamination with $\mathrm{CO}_{2}$, high-pressure water and chemicals. Equipment other than the spray ring on the $\mathrm{CO}_{2}$ decontamination system used for washdown of the deployment mast/WRM will be located in the utilities module, so it should be accessible for maintenance.

The decontamination ring will be located in the tank interface structure; remote access to it should be given consideration in both the structures and the end effector exchange module design. The components of the decontamination ring should be remotely replaceable.

The end effector exchange module shall have ports and $\mathrm{CO}_{2}$ service supplies to allow manual decontamination. The service supplies and ports shall be dispersed throughout the end effector exchange module to meet all the decontamination requirements.

During normal TWRS decontamination operations the atmosphere in the decontamination portion of the enclosure will be $\mathrm{CO}_{2}$ at a pressure of -0.3 to -1.0 in. of water. $\mathrm{CO}_{2}$ pellets shall be used for decontamination of the end effectors and mast components as follows:

- $\quad$ Pellet size

$1 / 8$ in. diameter $\times 1 / 4$ in. long

- $\quad$ Pellet density

$$
1.56 \mathrm{~g} / \mathrm{cm}^{3}
$$


- Pellet velocity 75 to $1,000 \mathrm{ft} / \mathrm{second}$

- $\quad$ Flow rate : $\quad 450$ SCFM at 250 psi.

Chemicals that may occasionally be applied internally to the confinement enclosure and equipment contained inside the enclosure, or TWRS components, require manual decontamination:

- Water spray

- 3 to 6 molar nitric acid

- 3 to 6 molar oxalic acid

- $\quad$ Turco Cleaning Compound 4502

- $\mathrm{CO}_{2}$ pellets directed under pressure of 250 psi. 


\section{CONCLUSIONS}

On the basis of this report, it was concluded that

1. Features must be incorporated into the final design of the TWRS to ensure positive removal of the deployment mast/WRM from the tank C-106 in the event of component failure.

2. Features incorporated into the design to provide capability of visual examination, repair, and replacement of components will provide cost effective and reliable operation of the TWRS.

3. Because Wallace (1993) is conceptual, it is lacking in detail, and there appears to be some contradiction with other descriptive sections that describe functional operation of the deployment mast and WRM with regard to their rotation about a vertical centerline. Descriptive sections indicate that the deployment mast and WRM rotate as an integral unit. This is supported by drawings that depict a drive mechanism for rotation of the deployment mast and by a WRM with a rectangular cross section and vertical rollers operating inside a deployment mast also of rectangular cross section. This is in conflict with the control system description that indicates rotational controls to the WRM.

4. Manned entry in to the end effector exchange module under strict radiation controls may be an option since the riser plug may be reinstalled on the tank and the cell may be decontaminated. 


\section{RECOMMENDATIONS}

1. Incorporate a maintenance module at the top end of the support mast to permit "glove box" maintenance operation on the deployment mast.

2. Incorporate a manhole window on the deployment mast to permit visual examination and limited maintenance on the upper end of the WRM. Bag-in/bag-out techniques could then be used to remove either the WRM by itself or the deployment mast/WRM system from the support mast.

3. Include in the performance specification, a requirement for preparation of a failure modes and effects analysis by the designer to ensure positive recovery in the event of component failure.

4. Further consider the design concept of routing the air conveyance hose into tank C-106 through a peripheral riser. Address the further complication of in-tank hook-up of the air conveyance hose to the end effector.

5. Locate the utilities module off the bridge to facilitate maintenance activities and provide a safer and more adequate environment for manual operation of the WRM from the local control center. This would also free space on the bridge for more appropriate equipment.

6. Include in the performance specification, a requirement for operation and maintenance manuals for all vendor-supplied equipment.

7. Ensure integral rotation of the deployment mast and WRM will permit placement of the rotational drive exterior to the deployment mast, which would facilitate maintenance activities.

8. Consider an extension of the deployment mast/WRM $\mathrm{CO}_{2}$ decontamination system to end effector exchange module cell decontamination.

9. Consider incorporating the WRM rotation joint at the top of the WRM because this may facilitate operation and maintenance.

10. Recommend end effector exchange module unit be configured like a cargo container with lifting points at the four corners and fork lift ports in addition to using bulkhead connectors, knife valves, and self-sealing quick disconnects to facilitate containment, handling, and operation.

11. Consider using skid-mounted equipment and lined cargo containers with removable external shielding for the air conveyance module.

12. For the contaminated equipment, recommend that top loading containers be used to simplify removal at the decontamination facility. All the equipment shall have lifting equipment and configurations to allow removal of the equipment remotely.

13. As with other TWRS and components, recommend the utilities module also be configured like a cargo container with lifting points and fork lift ports and cargo doors. 


\section{BIBLIOGRAPHY}

Brown, D. H., Maintenance and Operations Specification for the Light Duty Utility Arm (TWRS) Integrated System, WHC-S-0233, Rev. 0, Westinghouse Hanford Company, Richland, Washington.

Laurel, M. D., Operation/Maintenance Manual Cavijet Water Jet System, Tracor Hydronautics, Inc., 1986.

Parker Hannafin Corporation, Design Engineers Handbook, Parker Fluidpower Bulletin 0224-B1, Cleveland, Ohio.

Reutzel T. and Manhardt, J., Decontamination System Study for the Waste Retrieval System (TWRS), EG\&G Idaho, Inc., 1994.

Single-Shell Tank Waste Retrieval Manipulator System Development Team, Single-Shell Tank Waste Retrieval Manipulator System, DRAFT, Oak Ridge National Laboratory, Oak Ridge, Tennessee, 1992.

TWRS Development Team, Technical Specification for the Light Duty Utility Arm System Rev. 3, Wicatinghouse Hanford Company, Richland, Washington, 1994.

Wallace, D. A., Project W-340 Tank 241-C-106 Manipulator Retrieval System, WHC-SD-W340-ES-001, Westinghouse Hanford Company, Richland, Washington, August 1993. 


\section{II}
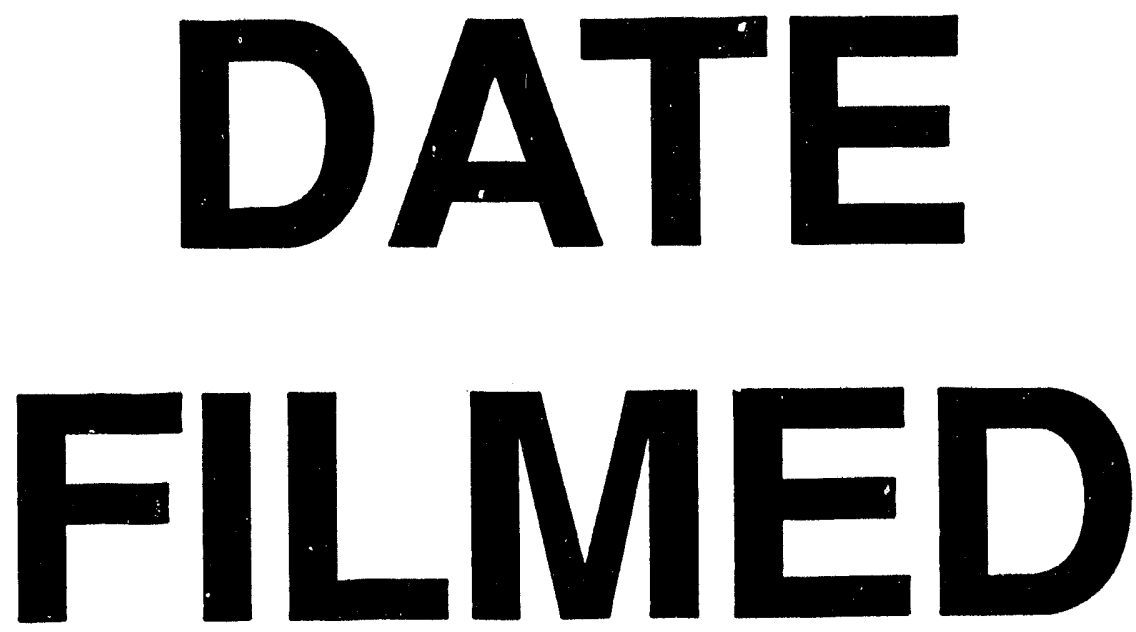

$8 / 23 / 94$
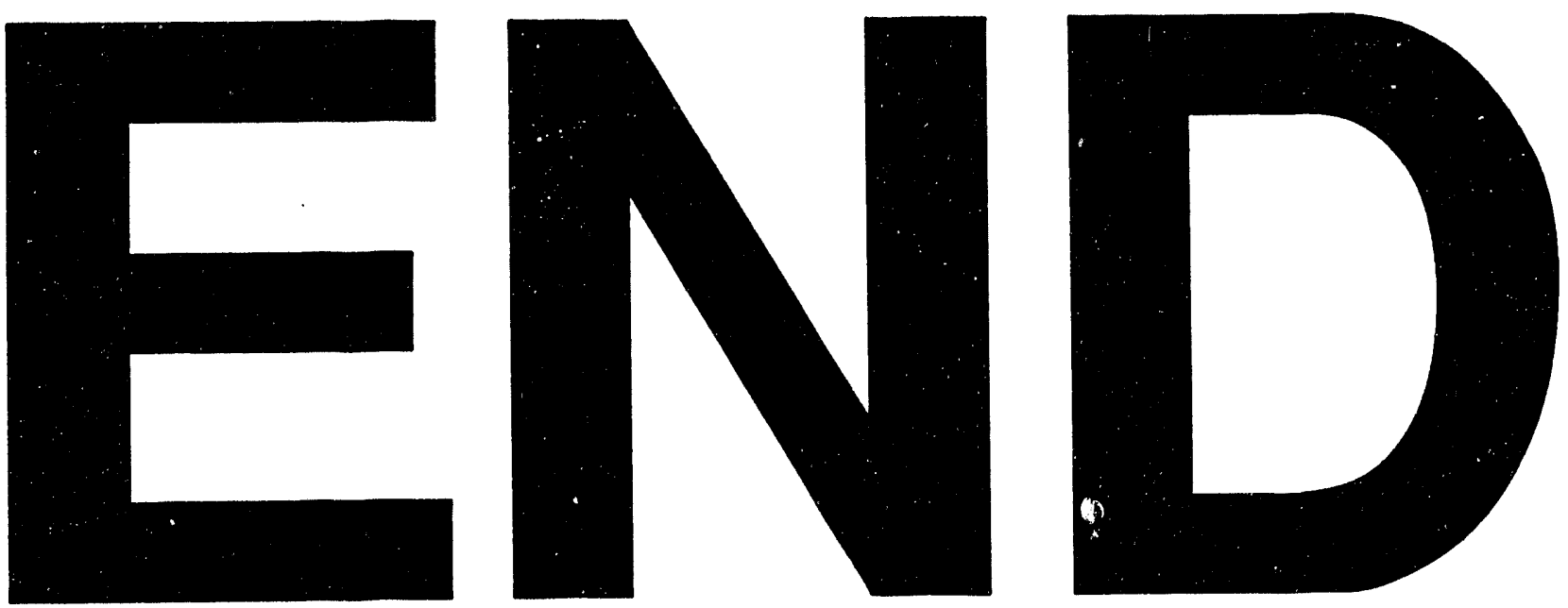
$\longrightarrow$

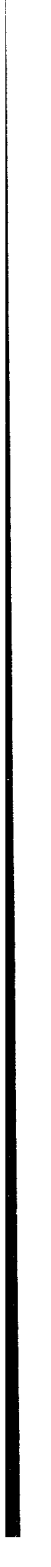

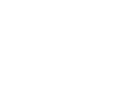

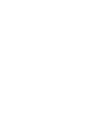
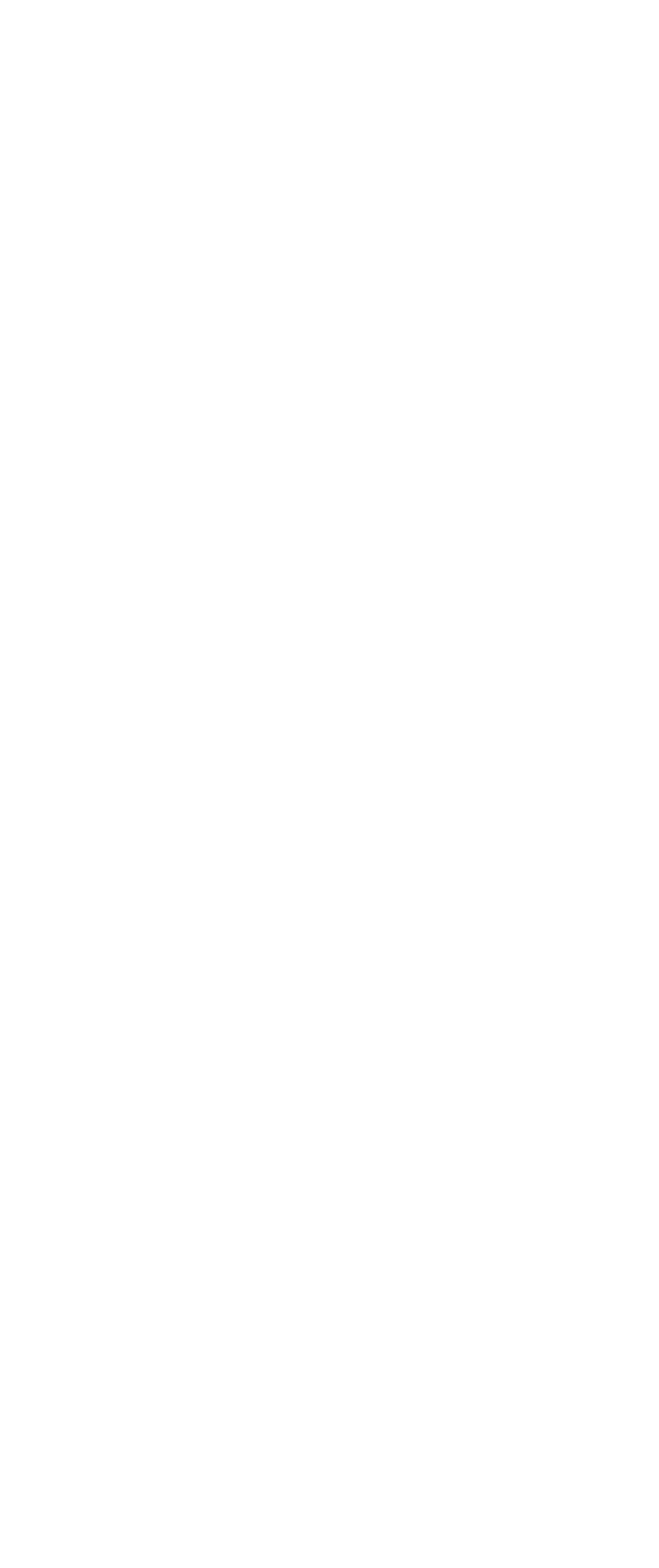